\title{
Intermolecular Interactions between Bottlebrush Polymers Boost the Protection of Surfaces against Frictional Wear
}

Jimmy Faivre ${ }^{1,4}$, Buddha Ratna Shrestha ${ }^{1}$, Guojun Xie, ${ }^{2}$ Mateusz Olszewski, ${ }^{2}$ Vahid Adibnia ${ }^{1}$, Florina Moldovan ${ }^{3}$, Alexandra Montembault ${ }^{4}$, Guillaume Sudre ${ }^{4}$, Thierry Delair ${ }^{4}$, Laurent David ${ }^{4}$, Krzysztof Matyjaszewski $^{2 *}$, Xavier Banquy ${ }^{1 *}$

${ }^{1}$ Canadian Research Chair in Bioinspired Materials, Faculty of Pharmacy, Université de Montréal, Montréal, Qc, Canada

${ }^{2}$ Center for Macromolecular Engineering, Department of Chemistry, Carnegie Mellon University, Pittsburgh, PA, USA

${ }^{3}$ Department of Stomatology, Faculty of Dentistry, CHU Sainte Justine Research Center, Montréal QC H3T 1C5, Canada

${ }^{4}$ Université de Lyon, Université Claude Bernard Lyon 1, CNRS UMR 5223, Ingénierie des Matériaux Polymères (IMP), 15 Boulevard Latarjet, 69622 Villeurbanne Cedex, France 


\begin{abstract}
Polymers exhibiting the bottlebrush (BB) architecture have excellent lubricating properties. However, in order to motivate their use in real life systems, they must also protect surfaces against frictional damage. In this article, we synthesized a library of polyzwiterrionic bottlebrush polymers of different architectures to explore the effect of intermolecular interactions on their conformation at interfaces and their tribological properties. Using the surface forces apparatus, we show that increasing the number of adhesives blocks on the BB polymers does not impact the friction coefficient on mica surfaces, $\mu$, which remained close to $\mu=0.02$ but drastically increased the threshold pressure, $P^{*}$, at which wear initiates from $P^{*}=0.4 \pm 0.1 \mathrm{MPa}$ up to $P^{*}=8.0 \pm 0.8 \mathrm{MPa}$. In mixtures of high molecular weight hyaluronic acid (HA) and BB polymers, a synergistic interaction between polymers occurred leading to a significant increase of $P^{*}$, independently of the BB polymer tested and even reaching superprotection for strongly interacting polymers (up to $P^{*}>14 \mathrm{MPa}$ ). Overall, these results show that strong intermolecular interaction between BB polymers and high molecular weight linear polymers is a promising strategy to create highly-protective lubricants.
\end{abstract}




\section{Introduction}

Using inspiration from nature, new materials able to perform under severe working conditions have been designed and tested successfully. Bioinspiration mimicks naturally-occurring nano, micro and macroscale structures which are remarkably efficient in resisting specific environmental stresses ${ }^{1}$.This concept has been applied to a myriad of materials ${ }^{1-3}$ with the aim to significantly enhance their mechanical, biological, physical or chemical properties. Bioinspiration has fostered a breadth of new technologies in many different fields. To name only a few, we can cite the development of superhydrophobic coatings inspired from the lotus leaf ${ }^{4}$, bioadhesive coatings or surfaces inspired from the Gecko's feet or the mussel's adhesive foot proteins, antifouling coatings making use of antiadhesive proteoglycans-mimicking polymers ${ }^{5-7}$, antireflective coatings mimicking the Moth's eyes structure $^{8-9}$, optically active surfaces inspired from the beetle scales structure ${ }^{10}$, advanced robotic devices able to evolve in complex environments using animal-like locomotion ${ }^{11}$, drug-delivery systems mimicking bacteria or immune cells $\mathrm{s}^{12-13}$, vaccines technologies using virus-like particles ${ }^{14}$ and biomaterial scaffolds mimicking bone or cartilage structure ${ }^{15-16}$.

Among all these examples of bioinspired materials, bottlebrush (BB) polymers, or macromolecular brushes, ${ }^{17-18}$ are promising materials for lubrication applications. Their architecture mimicks mucin-like proteoglycans found in synovial joints such as lubricin and aggrecans. These proteins are known to play a key role in the biolubrication and wear resistance of articular cartilage, and using a biomimetic approach, researchers have been able to design artificial lubricants displaying extremely low coefficients of friction $(\mathrm{CoF})$ and high wear protection of fragile soft surfaces. ${ }^{5,23}$ The structure of lubricin includes a highly hydrated central domain and two adhesive side domains ${ }^{24-31}$. The central domain consists of a polypeptide backbone bearing heavily glycosylated side chains composed of a significant amount of anionic carbohydrate units such as N- acetylneuraminic acid for lubricin and chondroitin and keratan sulfate moieties for aggrecan ${ }^{25,32}$. This central domain is known to impart excellent anti-adhesive properties to lubricin mostly due to strongly repulsive steric and hydration forces. On the other hand, adhesive domains are essential under severe working conditions. In the case of lubricin, the formation of the lubricant protective layer at the cartilage surface is provided by means 
of its affinity to fibronectin, type-II collagen or cartilage oligomeric matric protein ${ }^{33}$. For aggrecans, their attachment at one extremity to hyaluronic acid (HA) is mediated via the link protein which allows them to remain inside the cartilage matrix in order to increase its osmotic pressure. ${ }^{34-35}$

BB polymers mimic the branched architecture of these proteins with pendant chains grafted to a backbone $\mathrm{e}^{5,36}$ and often exceed $1 \mathrm{MDa}$ in molecular weight and $100 \mathrm{~nm}$ in contour length. Anchoring groups have also been incorporated at the extremities of these polymers ${ }^{5}$, or distributed along the polymer backbone $\mathrm{e}^{37-39}$ in order to improve their adhesion to different substrates. To ensure lubrication under severe working conditions such as boundary lubrication condition, anchoring groups must be designed to interact strongly with the surface they are meant to protect. Different types of anchoring groups have been probed making use of a large variety of molecular interactions such as electrostatic interactions using poly(L-Lysine $)^{40}, 2$-methacryloyloxyethyl trimethyl ammonium chloride ${ }^{41-42}$ or quaternized 2-(dimethylaminoethyl) methacrylate ${ }^{5}$, as well as hydrophobic interactions ${ }^{38}$, or covalent bounding. ${ }^{7}$

Many structural parameters of BB polymers can be varied to optimize their lubricating properties. A variety of bottle-brush domains have been reported using either uncharged pendant chains (poly(ethylene glycol), dextran) $)^{22,38,40}$, charged anionic ${ }^{43}$ or cationic ${ }^{44}$ pendant chains and zwitterionic (2-methacryloyloxyethyl phosphorylcholine $)^{5}$ pendant chains, all leading to a low CoF over several decades of applied normal forces and shear rates. Carillo et al. demonstrated that charged BB polymers exhibited a lower CoF compared to neutral polymers due to the additional osmotic pressure originated from their charges and surrounding counter-ions, a phenomenon that could be decreased with the ionic strength increase ${ }^{45}$ but not for polyzwitterionic polymers ${ }^{46}$. The length of the pendant chains as well as the backbone chain seem to also impact the lubrication of surfaces in vitro in a non trivial way. ${ }^{7}$

We recently showed that mixtures of BB polymers and hydrophilic, high molecular weight, and linear polymers exhibit synergistic wear protection properties. ${ }^{46}$ The synergy arises from strong, yet transient, intermolecular entanglements appearing during high compression/confinement. This synergy 
was observed with a monoblock BB polymer, designed to interact with the hydrophilic linear polymer only via physical entanglements and not via electrostatic, hydrophobic or any specific interactions. The aim of the present study is to explore the effect of the intermolecular interactions between linear and $\mathrm{BB}$ polymers on their lubricating and wear protecting capacity. We synthesized a series of BB polymers exhibiting adhesive blocks designed to interact strongly with polyanionic electrolytes such as hyaluronic acid. We characterized the tribological properties of the polymer mixtures with the surface forces apparatus in order to elucidate the interaction forces creating the synergistic effect and rationalize its properties.

\section{Materials and methods}

\section{Materials}

Methyl methacrylate (MMA, purity $=99 \%$, Sigma-Aldrich, USA) and 2-(trimethylsilyloxy)ethyl methacrylate (HEMA-TMS, purity $>96 \%$, Scientific Polymer Products Inc., USA), 2(dimethylamino)ethyl methacrylate (DMAEMA, 98\%, Sigma-Aldrich, USA) were passed through a column filled with basic alumina prior to use. 2-Methacryloyloxyethyl phosphorylcholine (MPC, purity $\geq 97 \%$, Sigma-Aldrich, USA) was recrystallized from acetonitrile and dried under vacuum overnight at room temperature before polymerization. Tetrahydrofuran (THF) was used after it was purified by tapping off from a solvent purification column right. Ethyl $\alpha$-bromoisobutyrate (EBiB, purity $\geq 98 \%$, Sigma-Aldrich, USA), $\alpha$-Bromoisobutyryl bromide $98 \%$ (BiBB, purity $\geq 98 \%$, SigmaAldrich, USA) copper(I) chloride $\left(\mathrm{Cu}^{\mathrm{I}} \mathrm{Cl}\right.$, purity $\geq 99.995 \%$ trace metals basis, Sigma-Aldrich, USA), copper(II) chloride $\left(\mathrm{Cu}^{\mathrm{II}} \mathrm{Cl}_{2}\right.$, purity $\geq 99.995 \%$ trace metals basis, anhydrous, Sigma-Aldrich, USA), 2,2'-bipyridyl (bpy, purity $\geq 99 \%$, Sigma-Aldrich, USA), 4,4'-Dinonyl-2,2'-dipyridyl (dNbpy, purity $\geq$ 97\%, Sigma-Aldrich, USA), potassium fluoride (KF, purity $\geq 99 \%$, spray-dried, Sigma-Aldrich, USA), tetrabutylamonium fluoride (TBAF, 1M solution in THF, Sigma-Aldrich, USA) and $\alpha$ bromoisobutyryl bromide (purity $=98 \%$, Sigma-Aldrich, USA were used without any additional purification. Ethylene bis(2-bromoisobutyrate) (2f-BiB) was synthesized according to procedures reported in the literature ${ }^{47}$. Ruby mica-sheets were purchased from S\&J Trading Inc. (Glen Oaks, NY, USA). Milli-Q quality water was obtained from a Millipore Gradient A10 S10 purification system 
(resistance $=18.2 \mathrm{M} \Omega . \mathrm{cm}, \mathrm{TOC} \leq 4 \mathrm{ppb})$. Phosphate buffer saline $(10 \mathrm{mM}$ Phosphate, $150 \mathrm{mM} \mathrm{NaCl}$ and $\mathrm{pH}$ 7.4) was prepared in our laboratory. 1.5 MDa sodium hyaluronate was obtained from lifecore biomedical (Minneapolis, USA).

\section{BB polymer characterizations}

Proton nuclear magnetic resonance ( ${ }^{1} \mathrm{H}$ NMR) spectroscopy was performed using Variant $400 \mathrm{MHz}$ spectrometer. In all cases deuterated chloroform $\left(\mathrm{CDCl}_{3}\right)$ was used as a solvent, except for bottlebrush polymer which was analyzed using deuterated methanol $\left(\mathrm{CD}_{3} \mathrm{OD}\right) .{ }^{1} \mathrm{H}$ chemical shifts are reported in parts per million (ppm) downfield from tetramethylsilane (TMS). Apparent molecular weights and molecular weight distributions measurements of polymers except bottle-brush polymer were measured by size exclusion chromatography (SEC) using Polymer Standards Services (PSS) columns (SDV: guard, $10^{5}, 10^{3}$, and $500 \AA$; GRAM: guard, $10^{5}, 10^{3}$, and $10^{2} \AA$ ), with THF or DMF as eluent at $35^{\circ} \mathrm{C}$ or $50{ }^{\circ} \mathrm{C}$ at a constant flow rate of $1.00 \mathrm{~mL} / \mathrm{min}$, and differential refractive index (RI) detector (Waters and Wyatt). The apparent number-average molecular weights $\left(M_{\mathrm{n}}\right)$ and molecular weight distribution $\left(M_{\mathrm{w}} / M_{\mathrm{n}}\right)$ were determined with a calibration based on linear poly(methyl methacrylate) (PMMA) standards and diphenyl ether as an internal standard. Hyaluronic acid apparent molecular weights and distributions measurements were assessed by aqueous SEC in 10mM PBS, pH 7.4, 150mM NaCl buffer using TSKgel columns (TSKgel G6000PW, particle size 12 $\mu \mathrm{m}$, and TSKgel G2500PW, particle size $12 \mu \mathrm{m}$ ) at a constant flow rate of $1.00 \mathrm{~mL} / \mathrm{min}$, and differential refractive index (RI) detector (Waters). The apparent number-average molecular weights $\left(M_{\mathrm{n}}\right)$ and molecular weight distribution $\left(M_{\mathrm{w}} / M_{\mathrm{n}}\right)$ were determined with a $\mathrm{dn} / \mathrm{dc}$ set at $0.16 \mathrm{~mL} / \mathrm{mg}$.

\section{AFM imaging}

The mono, di and triblock BB polymers were imaged by atomic force microscopy (Multimode Dimension 3100 AFM). The polymers were dissolved at a concentration of $15 \mu \mathrm{g} / \mathrm{mL}$ and deposited on a freshly cleaved mica surface. The BB polymers were left to adsorb and the supernatant was rinsed three times to isolate polymer single chains. The surface was nitrogen-dried prior to AFM measurements. The AFM equipped with nanoscope VIII controller (Digital instruments) was set on the peak force QNM mode. The Scanasyst-air tips were used for AFM imaging. 


\section{Synthetic synovial fluid formulation}

For all the next experimentations, the BB polymers were dissolved at a concentration of $100 \mu \mathrm{g} / \mathrm{mL}$ in a phosphate buffered saline (10 mM PBS, $150 \mathrm{mM} \mathrm{NaCl}$, pH 7.4). 1.5 MDa HA was added to the BB polymer solutions at a concentration of $1 \mathrm{mg} / \mathrm{mL}$ leading synthetic synovial fluids (SSF). SSF were left in solution in a dark container at $4{ }^{\circ} \mathrm{C}$.

\section{SFA normal forces profiles}

A Surface Forces Apparatus was used to measure the normal interaction forces, $F_{\mathrm{N}}$, as a function of the separation distance, $D$, between two opposing and atomically flat mica surfaces covered with $\mathrm{BB}$ polymer (SFA 2000, SurForce LLC, USA). $F_{\mathrm{N}}$ was determined by measuring the deflection of the spring cantilever with a spring constant of $482 \mathrm{~N} / \mathrm{m}$. The distance between the surfaces was assessed using the fringes of equal chromatic order (FECO) via multiple beam interferometry (MBI) calibrated with mica/mica air contact. The two mica surfaces were glued on glass cylinder with a curvature of 2 $\mathrm{cm}$, degassed for $1 \mathrm{~h}$ with nitrogen. $50 \mu \mathrm{L}$ of SSF were injected between the surfaces and left to adsorb for $1 \mathrm{~h}$. Water was added at the bottom of the SFA chamber to saturate the chamber and limit the SSF evaporation. In and out runs were recorded in triplicate with the motor set a constant speed at $1 \mathrm{~nm} / \mathrm{s}$. The fringes were analyzed using a in-house Matlab ${ }^{\circledR}$ routine.

\section{SFA friction forces measurement}

The friction forces, $F_{\mathrm{t}}$, were measured as a function of the normal forces, $F_{\mathrm{N}}$, using the SFA. A piezo bimorph drove the lower surface in a back and forth motion at a constant sliding frequency of $50 \mathrm{mHz}$ controlled by a function generator. The friction forces transmitted to the upper surface were detected by semi conductive strain gauges. Acquired data were recorded and processed using Origin ${ }^{\circledR}$ software. The separation distance and surface wear initiation were continuously recorded during the experiment using the FECO fringes position and shape. 


\section{Results and discussion}

We developed a library of BB polymers with a central brush block composed of poly(2methacryloyloxyethyl phosphoryl choline) (PMPC) pendant chains and an adhesive block made of

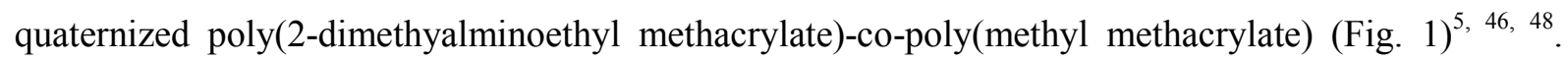
PMPC was chosen because of its excellent biocompatibility ${ }^{49}$ and tribological properties ${ }^{18,50}$. The adhesive block was designed to interact strongly with polyanionic electrolytes via electrostatic interactions between quaternized amine groups and negatively charged functional groups such as carboxylates. Three polymers were synthesized: a monoblock possessing only the bottle-brush central block, a diblock polymer exhibiting one lateral adhesive block and a triblock polymer exhibiting two lateral adhesive blocks.

A
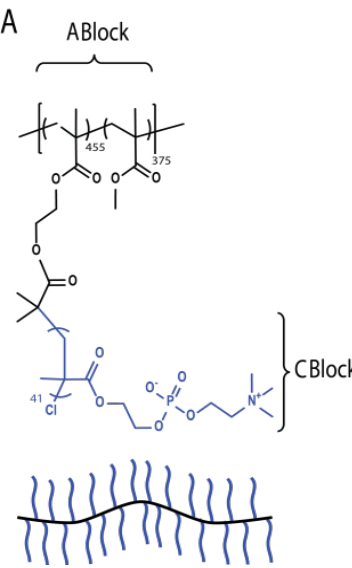

B ABlock BBlock
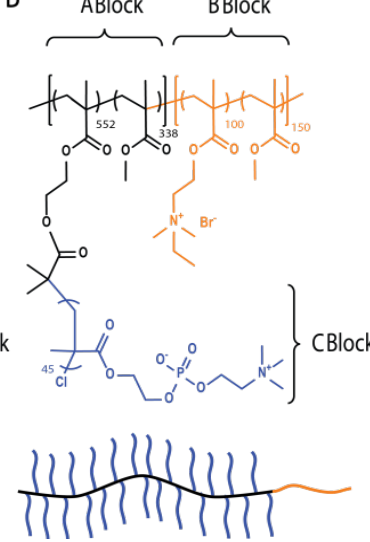
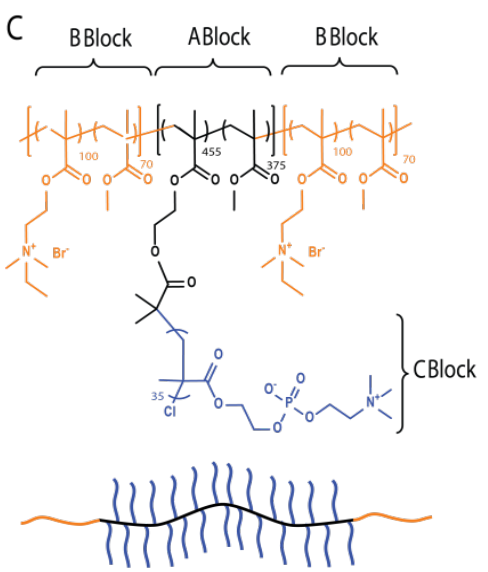

D

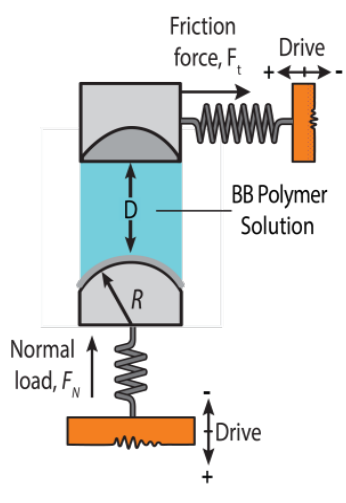

Figure 1. Chemical structure and schematic of the (A) mono, (B) di, and (C) triblock BB polymers. (D) Schematics of the SFA setup. For each BB polymer, the A block is the backbone bearing the densely grafted $\mathrm{C}$ block. The pendant chains are represented by the block $\mathrm{C}$. For BB polymers bearing anchoring groups (di and tri-block BB polymer), the B block represents the anchoring groups.

These polymers were dissolved at a concentration of $100 \mu \mathrm{g} / \mathrm{mL}$ in a PBS. The BB polymer solution was then injected in the SFA chamber prior to normal forces profiles measurement and tribotesting. High molecular mass $\mathrm{HA}\left(\mathrm{M}_{\mathrm{w}}=1.5 \mathrm{MDa}\right)$ at $1 \mathrm{mg} / \mathrm{mL}$ was also mixed to the BB polymers to characterize the possible synergy and interactions between the two polymers ${ }^{46}$. 
Mono and triblock BB polymers were synthesized by atom-transfer radical polymerization (ATRP) using the same bifunctional initiator ethylene bis(2-bromoisobutyrate) whereas the diblock BB polymer was initiated using the monofunctional ethyl $\alpha$-bromoisobutyrate ${ }^{51-52}$ (Scheme 1$)$. Both methyl methacrylate (MMA) and 2-(trimethylsilyloxy)ethyl methacrylate (HEMA-TMS) were copolymerized using the similar ratio of initiator/MMA/HEMA-TMS to lead to almost the same backbone length (Table 1). HEMA-TMS was used as initiator precursor and constituted about $50 \mathrm{~mol} \%$ of the backbone repeat unit (Table 1). This ratio was chosen to decrease the steric hindrance rising between pendant chain which can potentially lead to backbone chain scission.

Scheme 1. Schematic representation of the synthesis of mono, di and triblock BB polymers (For further details, see experimental section in the SI and Table 1)

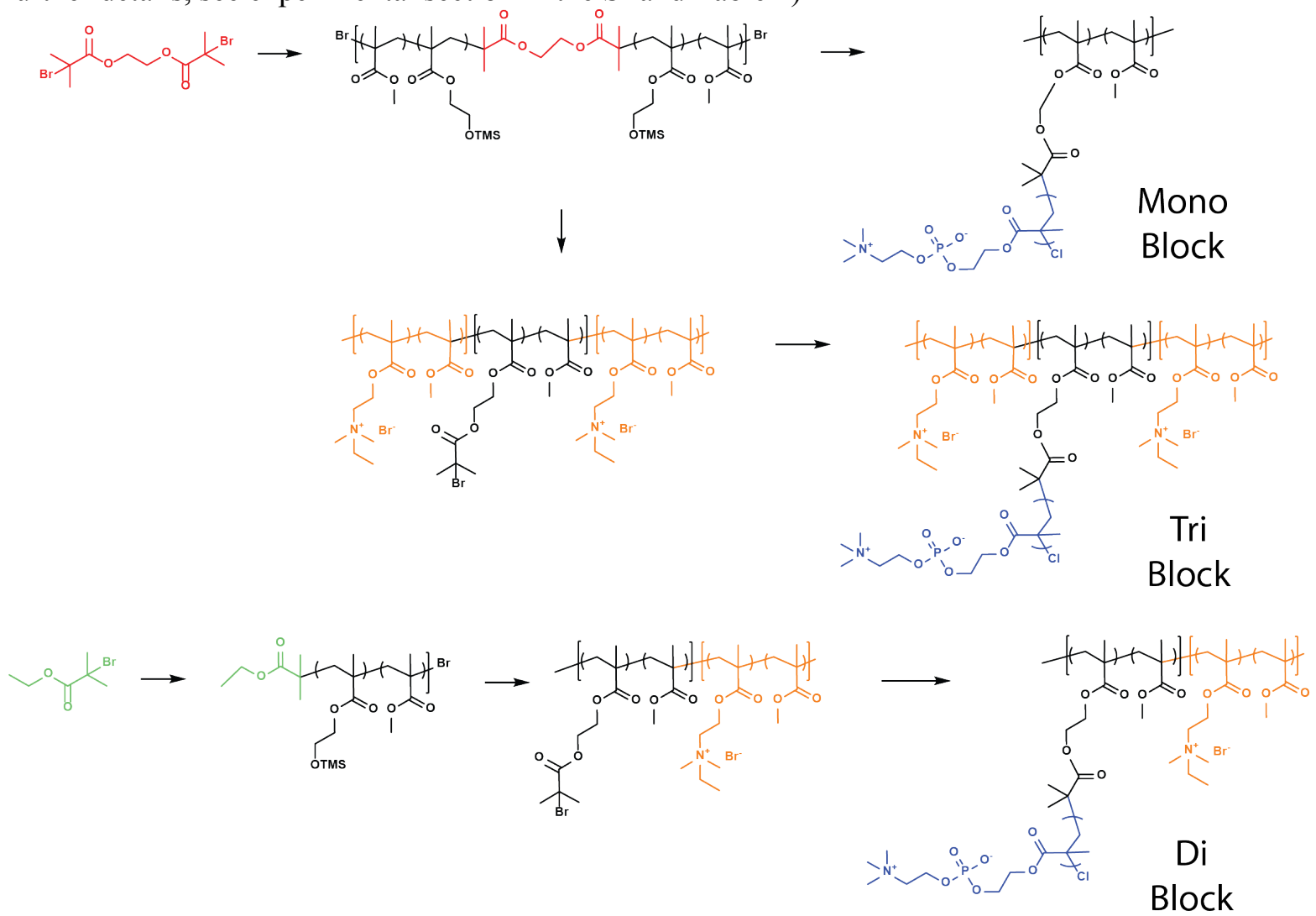

From the copolymer backbone, the reactive living ends were either left free for the monoblock BB polymer or used as initiators for the adhesive blocks composed of copolymer of MMA and 2(dimethylamino)ethyl methacrylate (DMAEMA) with ratios of DMAEMA/MMA $=1 / 1$ for the diblock and triblock polymers. DMAEMA was then quaternized to obtain a polycationic attachment 
group able to non-specifically bound to polyanionic electrolyte hyaluronic acid. The post modifications of the BB polymers backbone consisted of the removal of the protecting TMS groups and the addition of BiBB followed by the polymerization of the lateral chains of MPC. To ensure the same degree of polymerization (DP) of pendant chains in all polymers, the amount of MPC was adjusted to the number of initiating sites on the backbone. The DP of the MPC chains was monitored by the conversion of the MPC monomer and set at DP $\sim 40$ (Table 1).

Table 1. Summary of the BB polymers composition

\begin{tabular}{|c|c|c|c|c|c|c|c|}
\hline BB Polymer & $\begin{array}{c}\text { DP } \\
\text { centra } \\
1 \\
\text { block } \\
\mathrm{A}^{\mathrm{a}, \mathrm{b}}\end{array}$ & $\begin{array}{c}\text { Ratio } \\
\text { MMA/HEM } \\
\text { A-TMS }^{\mathrm{a}}\end{array}$ & $\begin{array}{c}\text { Molecular } \\
\text { mass Central } \\
\text { block A } \\
\mathrm{M}_{\mathrm{n}}(\mathrm{kg} / \mathrm{mol}) \\
\left(\mathrm{M}_{\mathrm{w}} / \mathrm{M}_{\mathrm{n}}\right)^{\mathrm{a}, \mathrm{b}}\end{array}$ & $\begin{array}{c}\text { DP of } \\
\text { Lateral } \\
\text { block B }\end{array}$ & $\begin{array}{c}\text { Ratio } \\
\text { MMA/DM } \\
\text { AEMA }^{\mathrm{a}}\end{array}$ & $\begin{array}{c}\text { Molecular } \\
\text { mass of the } \\
\text { lateral block } \\
\mathrm{B} \mathrm{M}_{\mathrm{n}} \\
(\mathrm{kg} / \mathrm{mol})^{\mathrm{a}}\end{array}$ & $\begin{array}{c}\text { DP } \\
\text { block } \\
\mathrm{C}^{\mathrm{a}}\end{array}$ \\
\hline Monoblock & 830 & $45 \%$ & $132(1.16)$ & $\mathrm{n} / \mathrm{a}$ & - & $\mathrm{n} / \mathrm{a}$ & 41 \\
\hline Diblock & 890 & $38 \%$ & $145(1.31)$ & 250 & $60 \%$ & 40 & 45 \\
\hline Triblock & 830 & $45 \%$ & $132(1.16)$ & $170 \times 2$ & $40 \%$ & $32 \times 2$ & 35 \\
\hline
\end{tabular}

${ }^{a}$ determined by ${ }^{1} \mathrm{H}$ NMR, ${ }^{b}$ measured by GPC

The BB polymer structure was assessed by AFM imaging (Fig. 2). Each polymer exhibited the characteristic linear structure of BB polymers with almost identical contour lengths $(\approx 140 \mathrm{~nm})$.

A

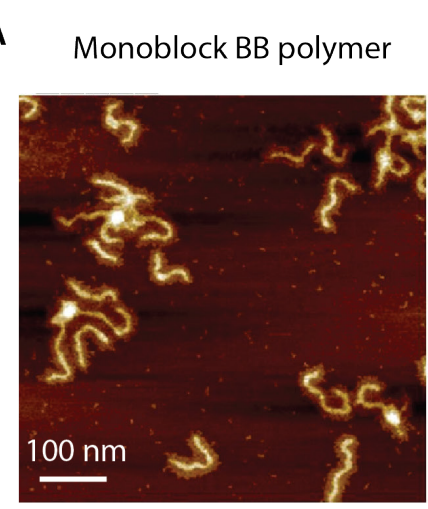

B

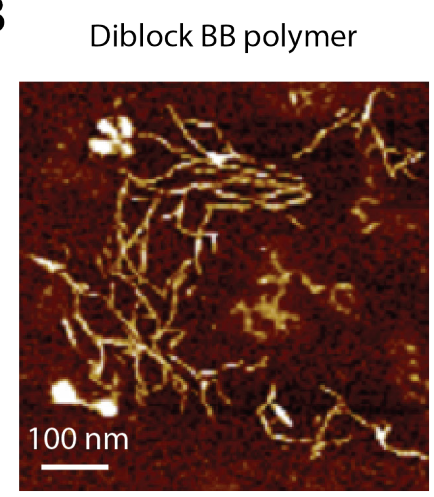

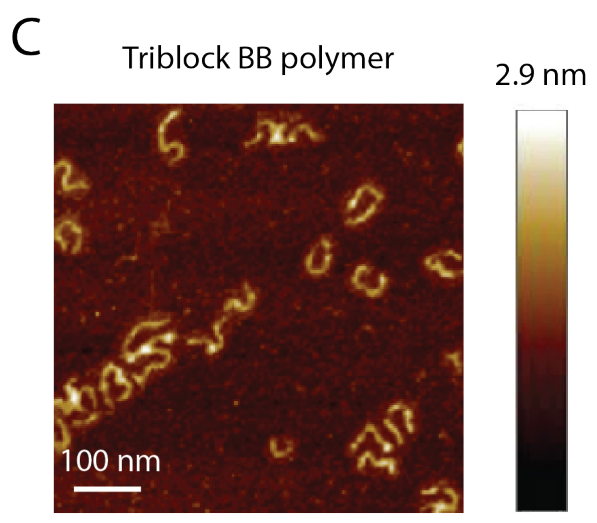

$-1.8 \mathrm{~nm}$

Figure 2. AFM pictures of the (A) monoblock, (B) di and (C) triblock BB polymers deposited on freshly cleaved mica surfaces at a concentration of $15 \mu \mathrm{g} / \mathrm{mL}$.

Normal forces profiles, $F_{\mathrm{N}} / \mathrm{R}$, as a function of the separation distance, $D$, between two mica surfaces immersed in a BB polymer solution at $100 \mu \mathrm{g} / \mathrm{mL}$ in PBS were then recorded and compared to forces 
profiles in presence of $\mathrm{HA}\left(\mathrm{M}_{\mathrm{w}}=1.5 \mathrm{MDa}\right.$ at $\left.1 \mathrm{mg} / \mathrm{mL}\right)$. In each experiment, the polymer mixture was let free to adsorb on the mica surfaces for $1 \mathrm{~h}$ prior to force measurements. For each BB polymer tested with or without HA, the approach and separation speeds of the surfaces were set at $\sim 1 \mathrm{~nm} / \mathrm{s}$. As can be seen in Fig. 3, the interaction profiles measured with all three BB polymers (no HA) was repulsive on approach as well as on separation (separation profiles are not shown for clarity). The onset of the interaction forces, i.e. the separation distance, $D_{\text {onset, }}$ at which the interaction force intensity is above the noise level, varies between 125 and $150 \mathrm{~nm}$ for the mono block and diblock polymers and was around $50 \mathrm{~nm}$ for the triblock polymer. As previously shown, ${ }^{46}$ the interaction forces rising from the monoblock polymer are reminiscent from the particular conformation of the polymer at the surface. The monoblock polymer adsorbed at one extremity of its backbone, leaving the other extremity free to move in the medium. Given the higher rigidity of the BB polymer compared to a linear random coil chain, the interaction force law between surfaces bearing end adsorbed BB polymers can be derived assuming that the polymer behaves as a rigid rod, end attached to the surface. ${ }^{48}$ In that formalism, the interaction forces can be described by the following equation: ${ }^{48}$

$\frac{F_{N}}{R} \approx \mathrm{k}_{\mathrm{B}} T \Gamma \ln \left(\frac{D_{\text {onset }}}{D}\right) \quad D<D_{\text {onset }}$

where $\Gamma$ is the effective density of adsorbed BB polymer and $k_{\mathrm{B}}$ the Boltzmann constant.

The rigid rod model predicts that the onset of interaction is independent of the grafting density of the polymer as previously confirmed experimentally. ${ }^{48}$ The similarity between the force profiles shown in Figures $3 \mathrm{~A}$ and $\mathrm{B}$ strongly suggest that the diblock polymer conformation is identical to the monoblock polymer. The onset of interaction, $D_{\text {onset }}$ (obtained using Eq. 1), being on average equal to twice the thickness of the polymer layer adsorbed on the surfaces (no interdigitation approximation), we can estimate a thickness of $65-75 \mathrm{~nm}$ for both monoblock and diblock polymer layers. Given that the contour length of the polymer is around $140 \mathrm{~nm}$ for both polymers, we can conclude that half of the polymer length is in contact with the mica surface while the other half is extending towards the medium. The similarities between the force profiles of these two polymers originate from similar brush conformation at the solid-liquid interface. The brush conformation of the monoblock polymer is 
rather peculiar since it has no terminal adhesive end block. Nevertheless, this conformation is highly favorable at high surface density of polymer due to lateral steric interactions between neighboring molecules.

For the triblock polymer, $D_{\text {onset }}=42 \mathrm{~nm}$ which is significantly shorter than the other two polymers and in good agreement with previous measurements reported in PBS for a similar triblock polymer. ${ }^{48} \mathrm{~A}$ shorter onset of interactions, corresponding to a polymer layer thickness of $21 \mathrm{~nm}$, indicates a drastically different conformation compared to the other two polymers. As shown previously, ${ }^{48}$ the conformation of the triblock polymer is close to a loop conformation, which is consistent with a shorter onset of interaction since the two adhesives blocks are expected to be strongly anchored onto the surface.

The mixtures of $\mathrm{HA}$ and the $\mathrm{BB}$ polymers presented marked differences compared to the BB polymers alone. Again, from Figure $3 \mathrm{~A}$ and $\mathrm{B}$, we can see that the monoblock and the diblock behave very similarly. The interaction force profile presents a long range portion with a $D_{\text {onset }}$ very similar to the BB polymer alone suggesting that this interaction regime is largely dominated by the interaction between BB polymer chain ends extending in the medium (distal layer interaction, as shown in the schematics). In this regime, the interaction forces are weaker compared to the BB polymer alone due to a lower concentration of adsorbed polymer at the mica/liquid interface. Using Eq. 1, we estimated the effective surface concentration of the monoblock and diblock BB polymer and found that their concentration decreased 40 to $70 \%$ when mixed with HA. A simple explanation for this behavior is the competitive adsorptions of BB polymer and HA on mica surfaces.

As the surfaces are brought closer together, a second interaction regime develops abruptly at a separation distance of $2 L_{\mathrm{s}}$. The value of $L_{\mathrm{s}}$ was estimated by extrapolating the interaction forces to zero force using a decaying power law and was $5 \mathrm{~nm}$ and $9 \mathrm{~nm}$ for the monoblock and the diblock respectively (dashed line in Figure 3). As previously reported, ${ }^{46}$ the value of $L_{\mathrm{s}}$ decreases with increasing the ionic strength of the medium which indicates the presence of HA in this layer. 
For the triblock polymer / HA mixture, the force profile was markedly different. The long range portion of the interaction forces observed for the previous two polymers was not present. The onset of interaction was much shorter and similar to the triblock BB polymer alone with $L_{\mathrm{s}}=42 \mathrm{~nm}$ but significantly more repulsive than the triblock alone. These observations suggest that the polymer layer on the surface is composed of triblock polymer in the loop conformation mixed with HA macromolecules (see schematic).
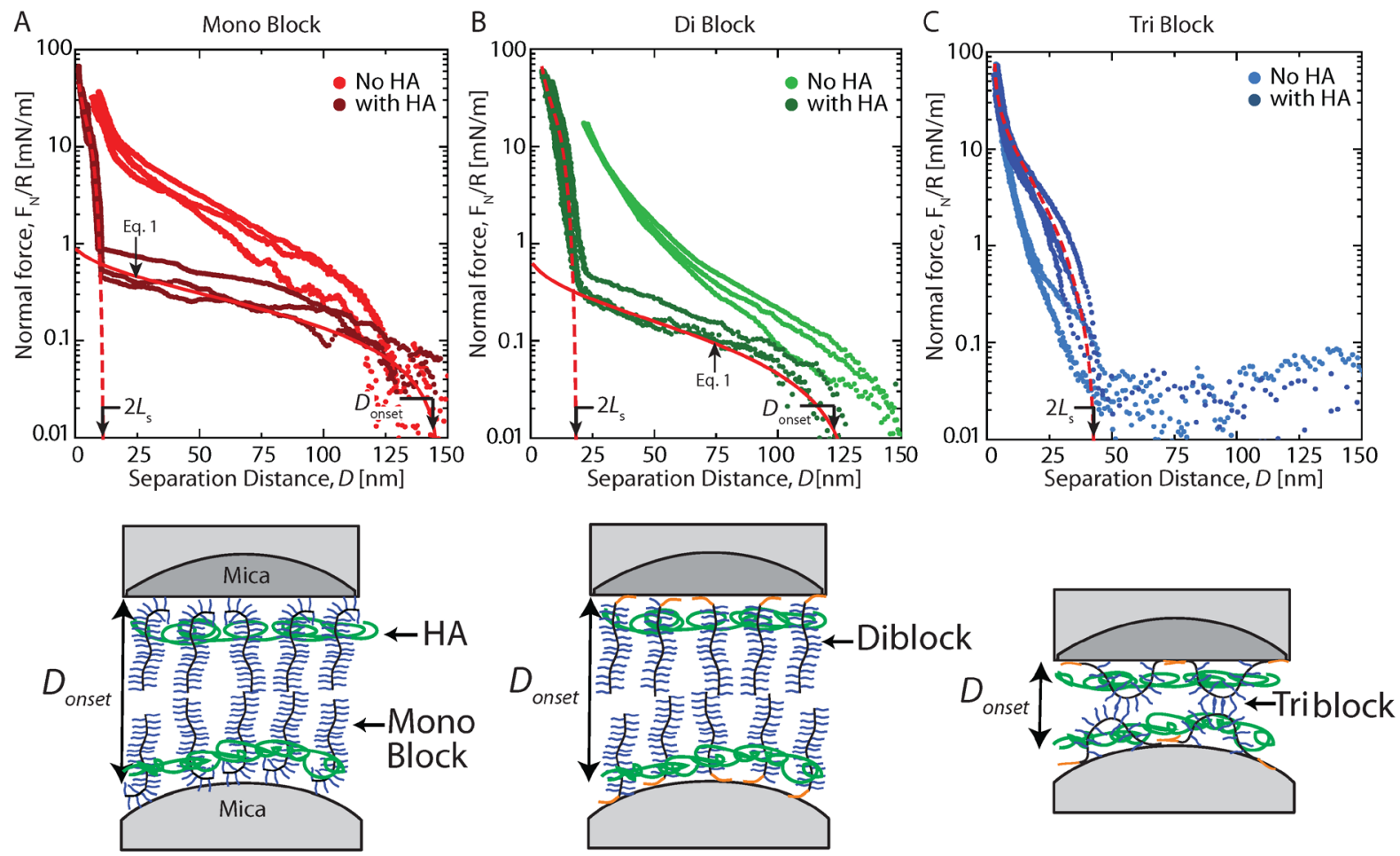

Figure 3. Normal force profiles of (A) mono-, (B) di-, and (C) tri-block BB polymers at $100 \mu \mathrm{g} / \mathrm{mL}$ in presence or absence of $1.5 \mathrm{MDa} \mathrm{HA}$ at $1 \mathrm{mg} / \mathrm{mL}$ between mica surfaces using the SFA. Data in panel A were adapted from ${ }^{46}$.

In order to quantify the impact of the molecular architecture of the BB polymer as well as its capacity to bind to HA on the tribological properties of the polymer mixture, a series of tests to assess the friction coefficient and threshold pressure at the onset of damage under shearing conditions was performed. 


\section{Bottle-Brush polymers without HA}
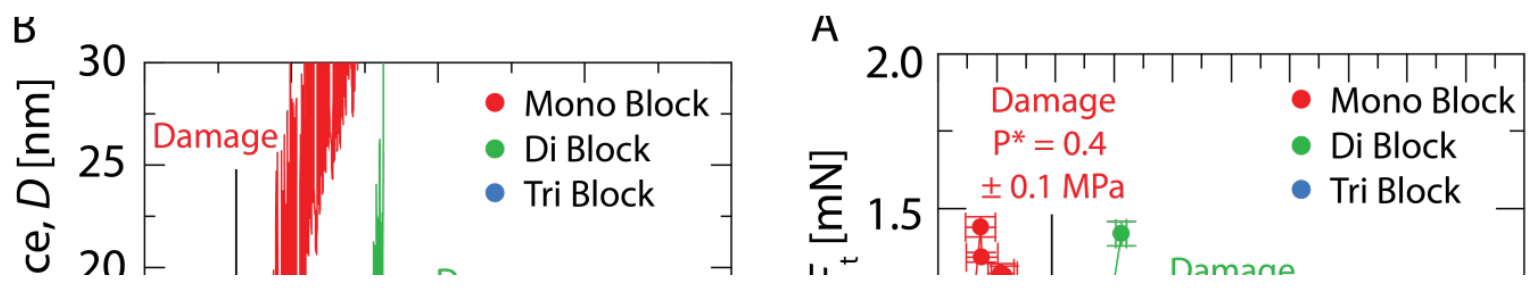

Figure 4. (A) Friction as a function of normal force for the mono, di and tri-blocks BB polymers at $100 \mu \mathrm{g} / \mathrm{mL}$ using the SFA. (B) Separation distance of the polymeric layer thickness as the function of time during tribotesting measured by the FECO fringes.

The friction force, $F_{\mathrm{t}}$, as a function of the normal applied force, $F_{\mathrm{N}}$, of the BB polymer solutions without HA in between atomically flat mica surfaces were first recorded (Fig. 4A). The results showed a linear relationship between the friction force and the normal force for all polymer solutions tested, which allowed to determine the coefficient of friction, $\mu$, defined as the ratio $\mu=F_{\mathrm{S}} / F_{\mathrm{N}}$. ${ }^{5,46}$ The measured value of the friction coefficient was $\mu \sim 0.013$ for the monoblock and diblock polymers and increased slightly for the triblock to 0.021 demonstrating that the lubrication properties of the BB polymers are entirely governed by the $\mathrm{BB}$ domain of the polymer rather than its lateral blocks. In contrast, the architecture of the polymer seems to have a much more pronounced effect on the onset of wear damage. Damage of mica surfaces by frictional wear can be easily detected in the SFA using multiple beam interferometry in order to monitor any sudden or gradual change in the shape of the Fringes of Equal Chromatic Order (FECO) ${ }^{48}$. As shown in Fig. 4A, the pressure onset of wear damage, $P^{*}$, increases with the number of adhesives blocks present in the polymer. We found that $P^{*}=0.4 \pm$ $0.1 \mathrm{MPa}$ for the monoblock, $P^{*}=1.5 \pm 0.7 \mathrm{MPa}$ for the diblock and $P^{*}=8.0 \pm 0.8 \mathrm{MPa}$ for the 
triblock. As a comparison, PBS alone has a $P^{*}=0.7 \mathrm{MPa} .{ }^{46}$ Monitoring of the polymer layer thickness with time allows to gain more insights on the origin of lubrication failure. As shown in Figure 4B, the thickness of the BB polymer lubricating film remained almost constant during the tribotest (before damage) and was equal to $2.5 \mathrm{~nm}$ for the monoblock and diblock and $3.5 \mathrm{~nm}$ for the triblock polymer. At $P=P^{*}$, the separation distance drastically increased due to surface damage and debris accumulation at the contact point. In the case of the mono and diblock polymers, the ultimate film thickness before damage is consistent with a monomolecular thin film of polymer while for the triblock polymer, the film thickness is more consistent with two polymer layers. Interestingly, in the case of the monoblock and diblock polymers, damage of the surfaces occurs when the surfaces are still separated by a polymer film. The rupture of the polymer film creates polymer particles at the point of contact which locally increases the pressure and deformation of the mica surface and triggers its fracture. As it will be shown, this mechanism does not occur in presence of HA.

\section{Bottle-Brush polymers with 1.5 MDa HA}
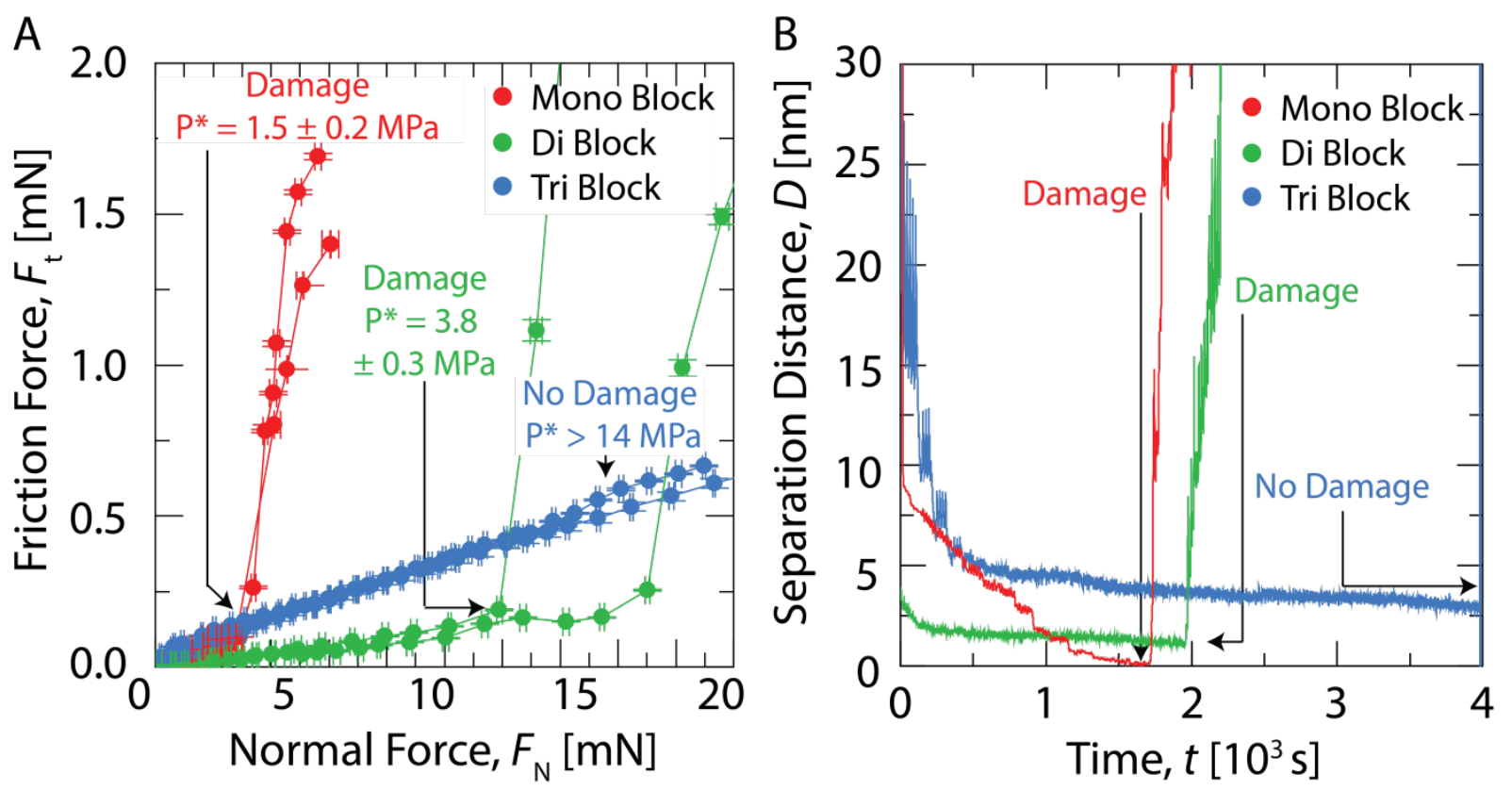

Figure 5. (A) Friction as a function of normal force for the mono, di and tri-blocks BB polymers at $100 \mu \mathrm{g} / \mathrm{mL}$ with $1.5 \mathrm{MDa} \mathrm{HA}$ at $1 \mathrm{mg} / \mathrm{mL}$ using the SFA. (B) Separation distance of the polymeric layer thickness as function of time during tribotesting. Each stepwise decrement of the separation distance corresponds to an increase of the applied load. 
The mixtures of HA and BB polymers were tested following the same protocol. Again, the friction forces increased linearly with the applied load for all three polymers but the corresponding friction coefficients were slightly different. For the monoblock and triblock polymers, $\mu=0.03$ and 0.035 respectively while for the diblock, $\mu=0.015$ (see figure 5A). These values are slightly higher than the measured values for the $\mathrm{BB}$ polymers alone which can be due to a concomitant decrease of $\mathrm{BB}$ polymer at the interface and an increase of HA concentration. This explanation is consistent with the observations from the normal force profiles where the presence of HA in the proximal layer was confirmed together with a smaller concentration of the BB polymer. The friction coefficient of grafted HA layers $(\mu \approx 0.5)$ is significantly higher than the BB polymers which rules out the possibility of total depletion of the BB polymers from the contact.

Differences between the polymer mixtures were again more apparent when comparing their wear protection capacity. For the HA / monoblock polymer mixture, initiation of wear was recorded at $P^{*}=$ $1.5 \pm 0.2 \mathrm{MPa}$, and it increased to $P^{*}=3.8 \pm 0.3 \mathrm{MPa}$ for the diblock whereas the triblock polymer mixture did not present any lubrication failure up to $P=14 \mathrm{MPa}$, which was the pressure limit reached by our setup. For the diblock and the triblock polymers, the thickness of the lubricating film remained constant at $1-1.5 \mathrm{~nm}$ and $2.5-3 \mathrm{~nm}$ respectively while it decreased continuously as the normal load was increased for the monoblock BB polymer / HA mixture until reaching the value of $0.3 \mathrm{~nm}$ at $P=P^{*}$ which corresponds to the thickness of a monolayer of water molecules (Fig. 5B). 

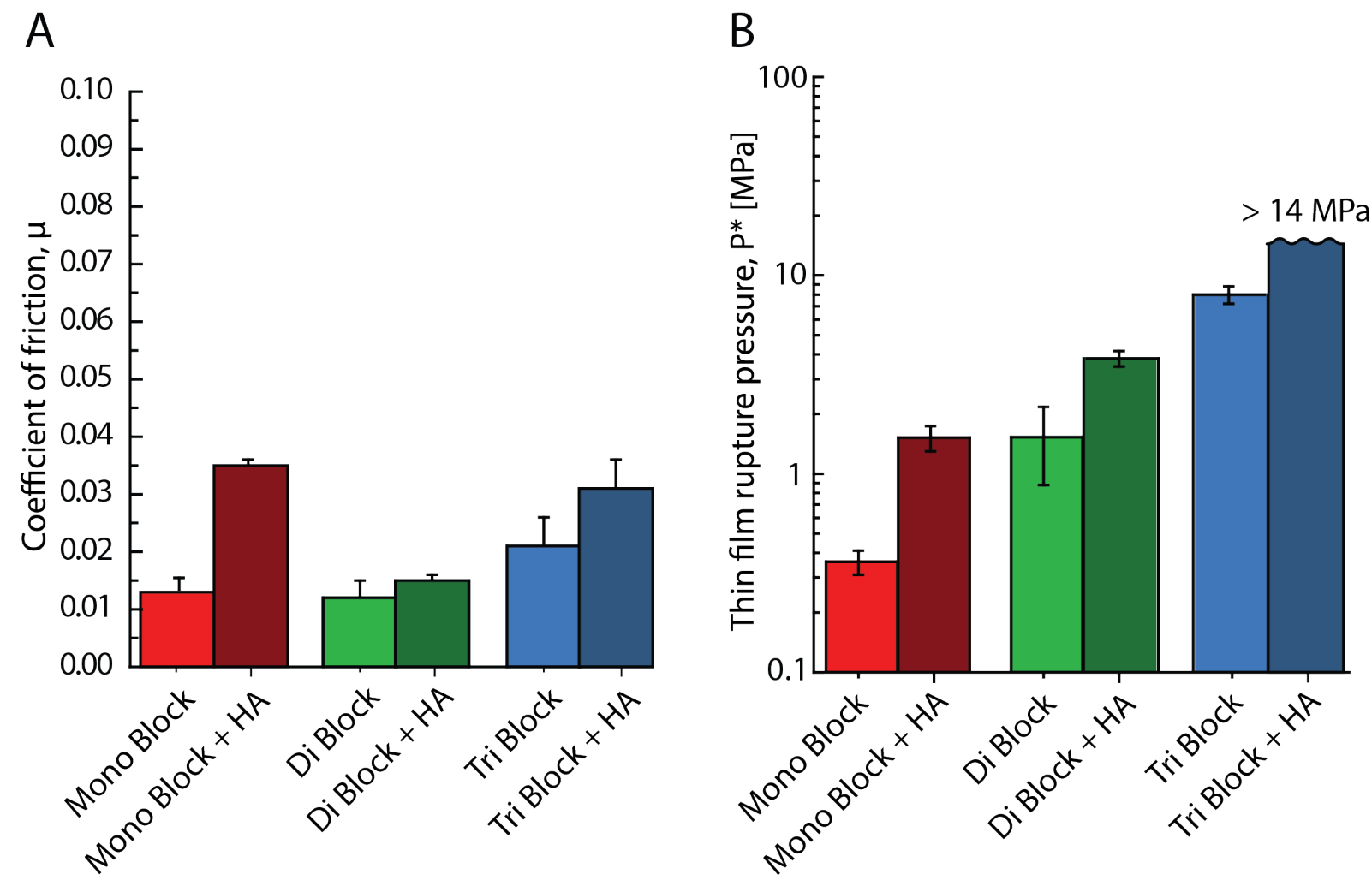

Figure 6. Histograms of the tribological results of the bioinspired fluid made of $100 \mu \mathrm{g} / \mathrm{mL}$ of $\mathrm{BB}$ polymer in presence or absence of $1.5 \mathrm{MDa} \mathrm{HA}$ at $1 \mathrm{mg} / \mathrm{mL}$. (A) CoF as a function of the lubricant system and (B) the lubricating film rupture pressure, $P^{*}$, of the different lubricating systems.

These tribostests allowed to draw some consistent trends differentiating the BB polymers alone and mixed with HA. When used alone, the BB polymers exhibit a low friction coefficient which value depends weakly on the architecture of the polymer. All three polymers had a friction coefficient between 0.01 and 0.03 (Fig. 6A), which is below the value of lubricin $(\mu=0.038)^{26}$ and also much smaller than synovial fluid $(\mu=0.2)^{53}$. The friction coefficient of HA solutions measured in the SFA was recently reported ${ }^{46}$ and was found to be identical to the friction coefficient of PBS ( $\left.\mu \approx 0.002\right)$. As previously reported, ${ }^{54} \mathrm{HA}$ does not adsorb strongly on mica surfaces and is easily removed from the mica surface if not grafted physically of chemically ${ }^{55}$ explaining why its tribological properties are similar to PBS. The BB polymer architecture seemed to control significantly the wear resistance, measured via the critical pressure of damage onset, $P^{*}$. As shown in Figure $6 \mathrm{~B}$, the values of $P^{*}$ increases with the number of adhesive blocks in the polymer non-linearly. This observation suggests 
that besides the differences in surface conformations observed between the different BB polymers, $P^{*}$ is solely controlled be the BB polymer interaction with the surface.

In presence of $\mathrm{HA}$, the friction coefficient of the mixtures was systematically higher than the $\mathrm{BB}$ polymer alone, although differences were rather small (between 0.01 and 0.03 ). The largest difference was observed between the monoblock polymer alone and when mixed with HA. The monoblock BB polymer is expected to have the weakest interaction with the mica surface and was found to be strongly depleted from the surface when mixed with HA. Normal force runs confirmed the presence of HA close to the surface, probably adsorbed on the mica surface via the formation of an intermolecular complex with the BB polymer. Friction coefficient of strongly adsorbed HA layers has been reported to be close to synovial fluid $(\mu=0.2)$, much higher to the values measured in our study. Therefore, the increase of the friction coefficient measured for the HA/BB polymer mixtures is expected to be due to the presence of HA and depletion of the BB polymer from the surface. For the diblock and triblock polymers, their interaction with HA is expected to be stronger via the positively charged groups present on the adhesive lateral blocks and the anionic carboxylic functions of HA. This electrostatic intermolecular interaction increases the cohesive strength of the interfacial polymer film and therefore its resistance to shear damage. The measured values of $P^{*}$ for the polymer mixtures were always higher than the values of the $\mathrm{BB}$ polymer alone and $\mathrm{HA}$ alone taken together $\left(P^{*}{ }_{\mathrm{HA}}+P^{*}{ }_{\mathrm{BB}}\right)$ indicating that a positive synergy is at play between the polymers. We can quantify such synergy via the synergy factor SF defined as:

$$
S F=\frac{P_{m i x t u r e}^{*}}{P_{H A}^{*}+P_{B B}^{*}}
$$

For the mono and diblock polymers, we found that $\mathrm{SF}=1.4$. As we already reported, ${ }^{46}$ the observed synergy is due to entanglements between the $\mathrm{BB}$ polymer and HA which transiently increases the cohesion between the two polymers under confinement. The presence of an adhesive polycationic block in the diblock BB polymer does not improve the synergy, certainly because parts the adhesive block adsorbs on the mica surface and therefore does not contribute efficiently to strengthen the cohesion of the lubricant film. 
Interestingly, the synergy factor increased for the triblock polymer / HA mixture. Considering that for this mixture, the highest applied pressure without any sign of damage was equal to $P=14 \mathrm{MPa}$, we can estimate a lower value of $\mathrm{SF}=1.7$, which is significantly higher than the other two BB polymer mixtures. This analysis shows that the synergy between the BB polymers and HA is greatly enhanced by the intermolecular bridges between HA and the triblock polymer.

Amongst all the identified contributions to the wear protection capacity of the polymer mixtures, intermolecular bridges seem to be far more important than the interaction between the BB polymer and the surface or even entanglements and intermolecular complexation between the polymers. This result suggest interesting new routes to design surface protecting lubricating fluids based on interacting polymer mixtures that could be tailored on demand to adapt to ambient conditions.

\section{Conclusions}

In summary, this study demonstrates the crucial role of intermolecular interactions between molecular brushes and HA on controlling the lubrication and wear resistance of surfaces. Indeed, although the bottlebrush block was shown to control the coefficient of friction, the adhesive blocks appear to tune the range of working conditions of the molecular brushes. The use of a non-specific anchoring group made of polycationic chain can be used to interact strongly with negatively charged polymers and surfaces to provide high wear resistance up to pressures much higher than those usually at work in biological systems (10 MPa or less). This work anticipates that other types of interaction could be used to tune even more finely the wear protection capacity of the polymer mixtures, for example using stimuli responsive adhesive groups, therefore opening a new dimension in the formulation of lubricating fluids.

\section{Supporting information}

The Supporting Information is available free of charge on the ACS Publication website at http://pubs.acs.org.

BB polymer synthesis route, NMR characterization. 


\section{Author information}

\section{Corresponding author}

*Email: xavier.banquy@umontreal.ca; matyjaszewski@cmu.edu

\section{Author contributions}

JF, GX synthesized and characterized the BB polymers; JF, BRS and VA performed the SFA work, JF and $\mathrm{XB}$ analyzed the polymer structure by AFM, LD; GS and TD performed aqueous GPC experiments; JF, GX, KM and XB wrote the manuscript. All authors have given approval to the final version of the manuscript.

\section{Acknowledgements}

XB acknowledges the financial support from CIHR (CRC and Bridge grants) and NSERC (Discovery grant). JF is grateful to the Arthritis Society, the French Embassy (Frontenac scholarship) and the Faculté des études supérieures et postdoctorales from the Université de Montréal for financial supports. BRS thanks the financial support of GRUM. GS and XB are grateful to the FRQNT for the Samuel de Champlain France-Quebec cooperation grant. KM acknowledges support from the NSF (DMR 1501324). This work has benefited from the facilities and expertise of the Liquid Chromatography Platform (Agnès Crépet, Institut de Chimie de Lyon) for the characterization of polymers.

\section{Notes}

The authors declare no competing financial interest

\section{References}

(1) Naleway, S. E.; Porter, M. M.; McKittrick, J.; Meyers, M. A. Structural Design Elements in Biological Materials: Application to Bioinspiration. Adv. Mater. 2015, 27, 5455-5476.

(2) Hwang, J.; Jeong, Y.; Park, J. M.; Lee, K. H.; Hong, J. W.; Choi, J. Biomimetics: forecasting the future of science, engineering, and medicine. Int. J. Nanomed. 2015, 10, 5701-5713.

(3) Green, J. J.; Elisseeff, J. H. Mimicking biological functionality with polymers for biomedical applications. Nature 2016, 540, 386-394. 
(4) Li, Y.; Li, L.; Sun, J. Bioinspired Self-Healing Superhydrophobic Coatings. Angew. Chem. 2010, 122, 6265-6269.

(5) Banquy, X.; Burdyńska, J.; Lee, D. W.; Matyjaszewski, K.; Israelachvili, J. Bioinspired Bottle-Brush Polymer Exhibits Low Friction and Amontons-like Behavior. J. Am. Chem. Soc. 2014, 136, 6199-6202.

(6) Lawrence, A.; Xu, X.; Bible, M. D.; Calve, S.; Neu, C. P.; Panitch, A. Synthesis and characterization of a lubricin mimic (mLub) to reduce friction and adhesion on the articular cartilage surface. Biomaterials 2015, 73, 42-50.

(7) Samaroo, K. J.; Tan, M.; Andresen Eguiluz, R. C.; Gourdon, D.; Putnam, D.; Bonassar, L. J. Tunable Lubricin-mimetics for Boundary Lubrication of Cartilage. Biotribology 2017, 9, 18-23.

(8) Sun, C.-H.; Jiang, P.; Jiang, B. Broadband moth-eye antireflection coatings on silicon. Appl. Phys. Lett. 2008, 92, 061112.

(9) Wilson, S. J.; Hutley, M. C. The Optical Properties of 'Moth Eye' Antireflection Surfaces. J. Mod. Opt. 1982, 29, 993-1009.

(10) Simonis, P.; Vigneron, J. P. Structural color produced by a three-dimensional photonic polycrystal in the scales of a longhorn beetle: Pseudomyagrus waterhousei (Coleoptera: Cerambicidae). Phys. Rev. E 2011, 83, 011908.

(11) Kim, S.; Laschi, C.; Trimmer, B. Soft robotics: a bioinspired evolution in robotics. Trends Biotechnol. 2013, 31, 287-294.

(12) Parodi, A.; Quattrocchi, N.; van de Ven, A. L.; Chiappini, C.; Evangelopoulos, M.; Martinez, J. O.; Brown, B. S.; Khaled, S. Z.; Yazdi, I. K.; Enzo, M. V.; Isenhart, L.; Ferrari, M.; Tasciotti, E. Synthetic nanoparticles functionalized with biomimetic leukocyte membranes possess cell-like functions. Nat. Nanotechnol. 2013, 8, 61-68.

(13) Yoo, J.-W.; Irvine, D. J.; Discher, D. E.; Mitragotri, S. Bio-inspired, bioengineered and biomimetic drug delivery carriers. Nat. Rev. Drug Discov. 2011, 10, 521-535.

(14) Zhang, P.; Chen, Y.; Zeng, Y.; Shen, C.; Li, R.; Guo, Z.; Li, S.; Zheng, Q.; Chu, C.; Wang, Z.; Zheng, Z.; Tian, R.; Ge, S.; Zhang, X.; Xia, N.-S.; Liu, G.; Chen, X. Virus-mimetic nanovesicles as a versatile antigen-delivery system. Proc. Natl. Acad. Sci. U. S. A. 2015, 112, 6129-6138.

(15) A, A.; Menon, D.; T. B, S.; Koyakutty, M.; Mohan, C. C.; Nair, S. V.; Nair, M. B. Bioinspired Composite Matrix Containing Hydroxyapatite-Silica Core-Shell Nanorods for Bone Tissue Engineering. ACS Appl. Mater. Interfaces 2017, 9, 26707-26718.

(16) Tatman, P. D.; Gerull, W.; Sweeney-Easter, S.; Davis, J. I.; Gee, A. O.; Kim, D.-H. Multiscale Biofabrication of Articular Cartilage: Bioinspired and Biomimetic Approaches. Tissue Eng., Part B 2015, 21, 543-559.

(17) Lee, H.-i.; Pietrasik, J.; Sheiko, S. S.; Matyjaszewski, K. Stimuli-responsive molecular brushes. Prog. Polym. Sci. 2010, 35, 24-44.

(18) Kobayashi, M.; Terayama, Y.; Kikuchi, M.; Takahara, A. Chain dimensions and surface characterization of superhydrophilic polymer brushes with zwitterion side groups. Soft Matter 2013, 9, 5138-5148.

(19) Pettersson, T.; Naderi, A.; Makuska, R.; Claesson, P. M. Lubrication properties of bottle-brush polyelectrolytes: An AFM study on the effect of side chain and charge density. Langmuir 2008, 24, 3336-3347.

(20) Russano, D.; Carrillo, J. M. Y.; Dobrynin, A. V. Interaction between Brush Layers of Bottle-Brush Polyelectrolytes: Molecular Dynamics Simulations. Langmuir 2011, 27, 11044-11051.

(21) Carrillo, J.-M. Y.; Brown, W. M.; Dobrynin, A. V. Explicit Solvent Simulations of Friction between Brush Layers of Charged and Neutral Bottle-Brush Macromolecules. Macromolecules 2012, 45, 88808891.

(22) Liu, X.; Thormann, E.; Dedinaite, A.; Rutland, M.; Visnevskij, C.; Makuska, R.; Claesson, P. M. Low friction and high load bearing capacity layers formed by cationic-block-non-ionic bottle-brush copolymers in aqueous media. Soft Matter 2013, 9, 5361-5371.

(23) Andresen Eguiluz, R. C.; Cook, S. G.; Tan, M.; Brown, C. N.; Pacifici, N. J.; Samak, M. S.; Bonassar, L. J.; Putnam, D.; Gourdon, D. Synergistic Interactions of a Synthetic Lubricin-Mimetic with Fibronectin for Enhanced Wear Protection. Front. Bioeng. Biotechnol. 2017, 5. 
(24) Jay, G. D.; Torres, J. R.; Warman, M. L.; Laderer, M. C.; Breuer, K. S. The role of lubricin in the mechanical behavior of synovial fluid. Proc. Natl. Acad. Sci. U.S.A 2007, 104, 6194-6199.

(25) Jay, G. D.; Waller, K. A. The biology of Lubricin: Near frictionless joint motion. Matrix Biol. 2014, $39,17-24$.

(26) Zappone, B.; Ruths, M.; Greene, G. W.; Jay, G. D.; Israelachvili, J. N. Adsorption, lubrication, and wear of lubricin on model surfaces: polymer brush-like behavior of a glycoprotein. Biophys. J. 2007, 92, 1693-1708.

(27) Coles, J. M.; Chang, D. P.; Zauscher, S. Molecular mechanisms of aqueous boundary lubrication by mucinous glycoproteins. Curr. Opin. Colloid Interface Sci. 2010, 15, 406-416.

(28) Majd, S. E.; Kuijer, R.; Kowitsch, A.; Groth, T.; Schmidt, T. A.; Sharma, P. K. Both Hyaluronan and Collagen Type II Keep Proteoglycan 4 (Lubricin) at the Cartilage Surface in a Condition That Provides Low Friction during Boundary Lubrication. Langmuir 2014, 14566-14572.

(29) Seror, J.; Zhu, L.; Goldberg, R.; Day, A. J.; Klein, J. Supramolecular synergy in the boundary lubrication of synovial joints. Nat. Commun. 2015, 6, 6497.

(30) Samsom, M.; Iwabuchi, Y.; Sheardown, H.; Schmidt, T. A. Proteoglycan 4 and hyaluronan as boundary lubricants for model contact lens hydrogels. J. Biomed. Mater. Res. B Appl. Biomater. 2017, 1329-1338.

(31) Swann, D. A.; Hendren, R. B.; Radin, E. L.; Sotman, S. L.; Duda, E. A. The lubricating activity of synovial fluid glycoproteins. Arthritis Rheum. 1981, 24, 22-30.

(32) Dedinaite, A. Biomimetic lubrication. Soft Matter 2012, 8, 273-284.

(33) Raj, A.; Wang, M.; Liu, C.; Ali, L.; Karlsson, N. G.; Claesson, P. M.; Dėdinaitè, A. Molecular synergy in biolubrication: The role of cartilage oligomeric matrix protein (COMP) in surface-structuring of lubricin. J. Colloid Interface Sci. 2017, 495, 200-206.

(34) Roughley, P.; Mort, J. The role of aggrecan in normal and osteoarthritic cartilage. J. Exp. Orthop. 2014, 1, 1-11.

(35) Kiani, C.; Chen, L.; Wu, Y. J.; Yee, A. J.; Yang, B. B. Structure and function of aggrecan. Cell Res. 2002, 12, 19-32.

(36) Bolton, J.; Bailey, T. S.; Rzayev, J. Large Pore Size Nanoporous Materials from the Self-Assembly of Asymmetric Bottlebrush Block Copolymers. Nano Lett. 2011, 11, 998-1001.

(37) Ramakrishna, S. N.; Espinosa-Marzal, R. M.; Naik, V. V.; Nalam, P. C.; Spencer, N. D. Adhesion and Friction Properties of Polymer Brushes on Rough Surfaces: A Gradient Approach. Langmuir 2013, 29, 15251-15259.

(38) Lee, S.; Spencer, N. D. Adsorption Properties of Poly(I-lysine)-graft-poly(ethylene glycol) (PLL-gPEG) at a Hydrophobic Interface: Influence of Tribological Stress, pH, Salt Concentration, and Polymer Molecular Weight. Langmuir 2008, 24, 9479-9488.

(39) Olanya, G.; Iruthayaraj, J.; Poptoshev, E.; Makuska, R.; Vareikis, A.; Claesson, P. M. Adsorption Characteristics of Bottle-Brush Polymers on Silica: Effect of Side Chain and Charge Density. Langmuir 2008, 24, 5341-5349.

(40) Rosenberg, K. J.; Goren, T.; Crockett, R.; Spencer, N. D. Load-Induced Transitions in the Lubricity of Adsorbed Poly(I-lysine)-g-dextran as a Function of Polysaccharide Chain Density. ACS Appl. Mater. Interfaces 2011, 3, 3020-3025.

(41) Claesson, P. M.; Makuska, R.; Varga, I.; Meszaros, R.; Titmuss, S.; Linse, P.; Pedersen, J. S.; Stubenrauch, C. Bottle-brush polymers: Adsorption at surfaces and interactions with surfactants. Adv. Colloid Interface Sci. 2010, 155, 50-57.

(42) Liu, X.; Dedinaite, A.; Rutland, M.; Thormann, E.; Visnevskij, C.; Makuska, R.; Claesson, P. M. Electrostatically Anchored Branched Brush Layers. Langmuir 2012, 28, 15537-15547.

(43) Raviv, U.; Giasson, S.; Kampf, N.; Gohy, J.-F.; Jerome, R.; Klein, J. Lubrication by charged polymers. Nature 2003, 425, 163-165.

(44) Dedinaite, A.; Pettersson, T.; Mohanty, B.; Claesson, P. M. Lubrication by organized soft matter. Soft Matter 2010, 6, 1520-1526. 
(45) Carrillo, J.-M. Y.; Russano, D.; Dobrynin, A. V. Friction between Brush Layers of Charged and Neutral Bottle-Brush Macromolecules. Molecular Dynamics Simulations. Langmuir 2011, 27, 1459914608.

(46) Faivre, J.; Shrestha, B. R.; Burdynska, J.; Xie, G.; Moldovan, F.; Delair, T.; Benayoun, S.; David, L.; Matyjaszewski, K.; Banquy, X. Wear Protection without Surface Modification Using a Synergistic Mixture of Molecular Brushes and Linear Polymers. ACS Nano 2017, 11, 1762-1769.

(47) Qin, S.; Matyjaszewski, K.; Xu, H.; Sheiko, S. S. Synthesis and Visualization of Densely Grafted Molecular Brushes with Crystallizable Poly(octadecyl methacrylate) Block Segments. Macromolecules 2003, 36, 605-612.

(48) Faivre, J.; Shrestha, B. R.; Xie, G.; Delair, T.; David, L.; Matyjaszewski, K.; Banquy, X. Unraveling the Correlations between Conformation, Lubrication, and Chemical Stability of Bottlebrush Polymers at Interfaces. Biomacromolecules 2017, 4002-4010.

(49) Yusa, S.-i.; Fukuda, K.; Yamamoto, T.; Ishihara, K.; Morishima, Y. Synthesis of Well-Defined Amphiphilic Block Copolymers Having Phospholipid Polymer Sequences as a Novel Biocompatible Polymer Micelle Reagent. Biomacromolecules 2005, 6, 663-670.

(50) Moro, T.; Takatori, Y.; Kyomoto, M.; Ishihara, K.; Kawaguchi, H.; Hashimoto, M.; Tanaka, T.; Oshima, H.; Tanaka, S. Wear resistance of the biocompatible phospholipid polymer-grafted highly cross-linked polyethylene liner against larger femoral head. J. Orthop. Res. 2015, 33, 1103-1110.

(51) Sheiko, S. S.; Sumerlin, B. S.; Matyjaszewski, K. Cylindrical molecular brushes: Synthesis, characterization, and properties. Prog. Polym. Sci. 2008, 33, 759-785.

(52) Matyjaszewski, K. Atom Transfer Radical Polymerization (ATRP): Current Status and Future Perspectives. Macromolecules 2012, 45, 4015-4039.

(53) Banquy, X.; Lee, D. W.; Das, S.; Hogan, J.; Israelachvili, J. N. Shear-Induced Aggregation of Mammalian Synovial Fluid Components under Boundary Lubrication Conditions. Adv. Funct. Mater. 2014, 24, 3152-3161.

(54) Benz, M.; Chen, N. H.; Jay, G.; Israelachvili, J. I. Static forces, structure and flow properties of complex fluids in highly confined geometries. Ann. Biomed. Eng. 2005, 33, 39-51.

(55) Yu, J.; Banquy, X.; Greene, G. W.; Lowrey, D. D.; Israelachvili, J. N. The Boundary Lubrication of Chemically Grafted and Cross-Linked Hyaluronic Acid in Phosphate Buffered Saline and Lipid Solutions Measured by the Surface Forces Apparatus. Langmuir 2012, 28, 2244-2250. 
Table of Contents
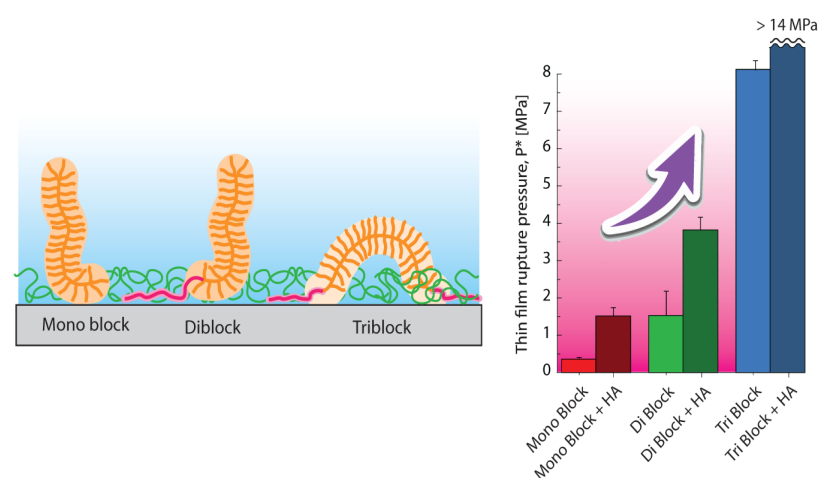


\section{Intermolecular Interactions between Bottlebrush Polymers Boost the Protection of Surfaces against Frictional Wear}

Jimmy Faivre ${ }^{1,4}$, Buddha Ratna Shrestha ${ }^{1}$, Guojun Xie, ${ }^{2}$ Mateusz Olszewski, ${ }^{2}$ Vahid Adibnia ${ }^{1}$, Florina Moldovan ${ }^{3}$, Alexandra Montembault ${ }^{4}$, Guillaume Sudre ${ }^{4}$, Thierry Delair ${ }^{4}$, Laurent David ${ }^{4}$, Krzysztof Matyjaszewski $^{2 *}$, Xavier Banquy ${ }^{1 *}$

${ }^{1}$ Canadian Research Chair in Bioinspired Materials, Faculty of Pharmacy, Université de Montréal, Montréal, Qc, Canada

${ }^{2}$ Center for Macromolecular Engineering, Department of Chemistry, Carnegie Mellon University, Pittsburgh, PA, USA

${ }^{3}$ Department of Stomatology, Faculty of Dentistry, CHU Sainte Justine Research Center, Montréal QC H3T 1C5, Canada

${ }^{4}$ Université de Lyon, Université Claude Bernard Lyon 1, CNRS UMR 5223, Ingénierie des Matériaux Polymères (IMP), 15 Boulevard Latarjet, 69622 Villeurbanne Cedex, France 
Table of Contents

Experimental procedures

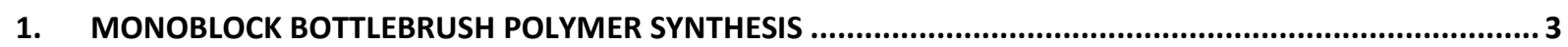

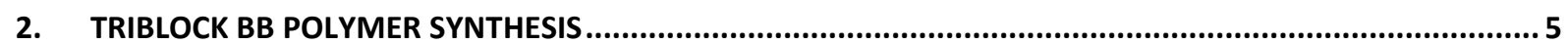

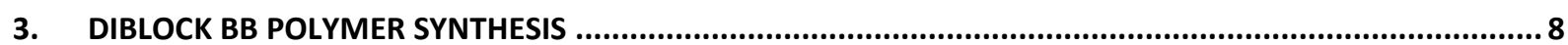




\section{Experimental procedures}

\section{Monoblock bottlebrush polymer synthesis (Figure S1)}

Synthesis of poly(HEMA-TMS) 459-co-PMMA $_{370}$ (A block). A dry 25 mL Schlenk flask was charged with bis(2-bromoisobutyrate) (2f-BiB, $25.8 \mathrm{mg}, 0.0718 \mathrm{mmol}), \mathrm{Cu}^{\mathrm{II}} \mathrm{Cl}_{2}(7.8 \mathrm{mg}$, $0.057 \mathrm{mmol})$, dNbpy (0.294 g, $0.718 \mathrm{mmol})$, HEMA-TMS (23.2 g, $25.0 \mathrm{~mL}, 115 \mathrm{mmol})$, MMA (11.5 g, $12.3 \mathrm{~mL}, 115 \mathrm{mmol})$ and anisole $(4.1 \mathrm{~mL})$. The solution was degassed by three freeze-pump-thaw cycles. During the final cycle, the flask was filled with nitrogen and $\mathrm{Cu}^{\mathrm{I}} \mathrm{Cl}$ (28.4 $\mathrm{mg}, 0.287 \mathrm{mmol}$ ) was quickly added to the frozen reaction mixture. The flask was sealed, evacuated and back-filled with nitrogen five times, and then immersed in an oil bath at $70{ }^{\circ} \mathrm{C}$. Reaction was stopped when the monomer conversion reached $25.9 \%$. The monomers consumption was calculated by the integration of MMA and HEMA-TMS vinyl groups signal $\left(\mathrm{CHH}=\mathrm{C}-\mathrm{CH}_{3}, 6.11 \mathrm{ppm}\right.$ or $\left.5.56 \mathrm{ppm}\right)$ against the internal standard (anisole, $o, p-\mathrm{Ar}-\mathrm{H}, 6.91$ ppm). The A block was purified by three precipitations from hexane, dried under vacuum for $16 \mathrm{~h}$ at room temperature, and analyzed by ${ }^{1} \mathrm{H}$ NMR spectroscopy. The ratio of PMMA ( $s$, broad, CO-O-CH$H_{3}, 3.54-3.68 \mathrm{ppm}$ ) to $\mathrm{P}\left(\mathrm{HEMA}-\mathrm{TMS}\right.$ ) (s, broad, O- $\mathrm{CH}_{2}-\mathrm{CH}_{2}-\mathrm{O}, 3.72-3.85$ ppm) peaks resulted in the polymer composition, $\mathrm{P}(\mathrm{HEMA}-\mathrm{TMS})_{459}$-co-PMMA 370 . Apparent molecular weights were determined using THF SEC: $M_{n}=82,200, M_{w} / M_{n}=1.16$.

Synthesis of polyBiBEM 459 -co-PMMA 370 (A Block macroinitiator, A MI). The polymer, A block (0.687 g, containing $2.42 \mathrm{mmol}$ of HEMA-TMS units), potassium fluoride $(0.171 \mathrm{~g}$, $2.90 \mathrm{mmol})$ and 2,6-di-tert-butylphenol $(49.8 \mathrm{mg}, 0.242 \mathrm{mmol})$ were placed in a $50 \mathrm{ml}$ round bottom flask. The flask was sealed, flushed with nitrogen, and dry THF (20 mL) was added. The mixture was cooled in an ice bath to $0{ }^{\circ} \mathrm{C}$, tetrabutylammonium fluoride solution in THF (1M, $0.02 \mathrm{~mL}, 0.02 \mathrm{mmol}$ ) was injected to the flask, followed by the drop-wise addition of 2bromoisobutyryl bromide $(0.36 \mathrm{~mL}, 2.9 \mathrm{mmol})$. After the addition the reaction mixture was allowed to reach room temperature and stirring was continued for $24 \mathrm{~h}$. The solids were 
filtered off, and the solution was precipitated into methanol:water (70:30, v/v\%). The precipitate was re-dissolved in chloroform and passed through a short column filled with basic alumina. The filtrate was re-precipitated three times from chloroform into hexanes and dried under vacuum overnight at room temperature.

Synthesis of poly[(BiBEM $\left.{ }_{400}-g-\mathrm{MPC}_{41}\right)$-stat-MMA $\left.{ }_{400}\right]$ (Monoblock BB polymer). A dry 5 mL Schlenk flask was charged with polymer A MI (10.2 mg, $2.8 \mu \mathrm{mol}$ of BiBEM), 2methacryloyloxyethyl phosphorylcholine (2.5 g, $8.5 \mathrm{mmol}), 2$,''-bipyridyl (15.0 mg, 0.0960 $\mu \mathrm{mol}$ ), $\mathrm{Cu}^{\mathrm{II}} \mathrm{Cl}_{2}$ (as a stock solution, $0.76 \mathrm{mg}, 0.056 \mathrm{mmol}$ ), acetonitrile (3.0 mL) and methanol (7.0 mL). The solution was degassed by three freeze-pump-thaw cycles. After the final cycle $\mathrm{Cu}^{\mathrm{I}} \mathrm{Cl}(4.2 \mathrm{mg}, 0.042 \mu \mathrm{mol})$ was added followed by thawing reaction mixture under nitrogen atmosphere, and the flask was immersed in an oil bath thermostated at $50{ }^{\circ} \mathrm{C}$. The reaction was stopped by exposing the solution to air when the monomer conversion reached $13.8 \%$, achieving the monoblock BB polymer. The brush was purified by dialysis against $\mathrm{MeOH}$ for $48 \mathrm{~h}$ using tubes with a pore size molar mass cut off $10,000 \mathrm{kDa}$. The Monomer conversion was calculated by ${ }^{1} \mathrm{H}$ NMR analysis, resulting in the average degree of polymerization of the side chains, $\mathrm{DP} \sim 41$. 


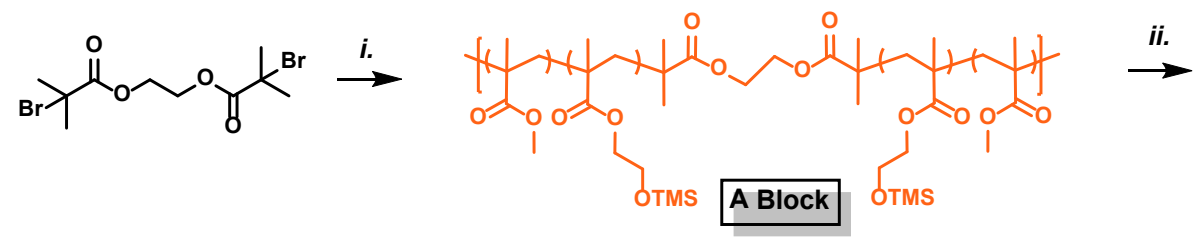

i. MMA, HEMA-TMS, $\mathrm{CuCl} / \mathrm{CuCl}_{2} / \mathrm{dNbpy}$, anisole, $70^{\circ} \mathrm{C}$

ii. MMA, DMAEMA, $\mathrm{CuCl} / \mathrm{CuCl}_{2} / \mathrm{dNbpy}$, anisole, $60^{\circ} \mathrm{C}$
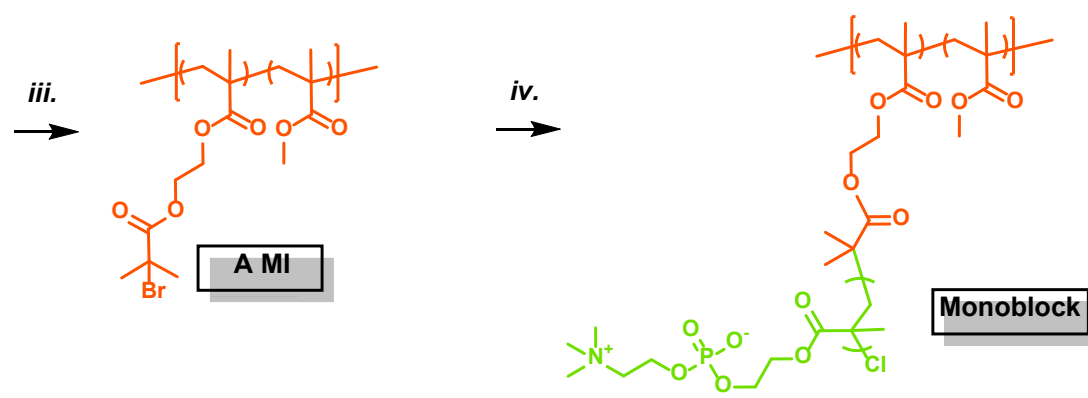

iii. 2,6-DTBP, KF, TBAF, BiBBr, DMF, $0^{\circ} \mathrm{C}-\mathrm{rt}$

iv. MPC, $\mathrm{CuCl} / \mathrm{CuCl}_{2} / \mathrm{bpy}$, methanol, $50^{\circ} \mathrm{C}$

Figure S1. Synthesis of the monoblock BB polymer

\section{Triblock BB polymer synthesis (Figure S2)}

Synthesis of poly[(DMAEMA98-stat-MMA 65$)-b-\left(\right.$ HEMA-TMS $_{459}$-stat-MMA 370$)-b$ (DMAEMA98-Stat-MMA ${ }_{65}$ )] (BAB). A dry $10 \mathrm{~mL}$ Schlenk flask was charged with the previous A block (1.02 g, $0.0081 \mathrm{mmol}$ ), $\mathrm{Cu}^{\mathrm{II}} \mathrm{Cl}_{2}$ (as a stock solution, $0.54 \mathrm{mg}, 4.0 \mu \mathrm{mol}$ ), dNbpy (0.0330 g, 0.0808 mmol), DMAEMA (2.03 g, $2.17 \mathrm{~mL}, 12.9$ mmol), MMA (1.29 g, $1.38 \mathrm{~mL}, 12.9 \mathrm{mmol})$ and anisole $(3.6 \mathrm{~mL})$. The solution was degassed by three freeze-pumpthaw cycles. During the final cycle, the flask was filled with nitrogen and $\mathrm{Cu}^{\mathrm{I}} \mathrm{Cl}(0.0034 \mathrm{~g}$, $0.035 \mathrm{mmol}$ ) was quickly added to the frozen reaction mixture. The flask was sealed, evacuated and back-filled with nitrogen five times, and then immersed in an oil bath at $60{ }^{\circ} \mathrm{C}$. Reaction was stopped via exposure to air when the monomer conversion reached $15.3 \%$. The product was precipitated from hexanes (twice) and water, re-dissolved in chloroform and passed through neutral alumina. The solvent was removed and the purified product was dried overnight under vacuum at room temperature. The ${ }^{1} \mathrm{H}$ NMR spectra of a pure BAB was used to evaluate its final composition, giving poly[(DMAEMA ${ }_{98}$-stat-MMA 65$)-b-\left(\mathrm{HEMA} \mathrm{TMS}_{459^{-}}\right.$ 
stat-MMA $\left.{ }_{370}\right)-b-\left(\mathrm{DMAEMA}_{98}-\right.$ stat-MMA 65$\left.)\right]$ (BAB). The structure of the polymer was determined from the ratio of selected polymer signals: PMMA ( $s$, broad, $\mathrm{CO}-\mathrm{O}-\mathrm{CH}_{3}, 3.54-$ $3.68 \mathrm{ppm}), \mathrm{P}(\mathrm{HEMA}-\mathrm{TMS})\left(\mathrm{s}\right.$, broad, $\left.\mathrm{O}-\mathrm{CH}_{2}-\mathrm{CH}_{2}-\mathrm{O}, 3.72-3.85 \mathrm{ppm}\right)$ and PDMAEMA ( $m$, $\left.\mathrm{CH}_{2}-\mathrm{NMe}_{2}, 2.55-2.65 \mathrm{ppm}\right)$. Apparent molecular weights were obtained using THF SEC: $M_{n}$ $=110,000, M_{w} / M_{n}=1.33$.

\section{Synthesis of poly[(qDMAEMA ${ }_{98}$-stat-MMA 65$)-b$-(HEMA-TMS ${ }_{459}$-stat-MMA 370$)-b-$} (qDMAEMA98-stat-MMA ${ }_{65}$ )] (quaternized BAB, qBAB). BAB (0.8962 g, containing 1.16 mmol DMAEMA units) was placed in $50 \mathrm{~mL}$ flask and dissolved in acetone $(25 \mathrm{~mL})$. The solution was cooled in an ice bath to $0{ }^{\circ} \mathrm{C}$, followed by a slow addition of bromoethane $(0.48$ $\mathrm{g}, 0.33 \mathrm{~mL}, 4.4 \mathrm{mmol})$. The reaction was stirred at room temperature for the next $48 \mathrm{~h}$. The solvent was removed and the product was dried under vacuum at room temperature. ${ }^{1} \mathrm{H}$ NMR spectra of the product, $\mathbf{q B A B}$, showed the quantitative quaternization of $-\mathrm{NMe}_{2}$ groups, as confirmed by the disappearance of signals corresponding to methylene $\left(\mathrm{CH}_{2}-\mathrm{NMe}_{2}, 2.55-2.65\right.$ ppm) and methyl groups $\left(m, \mathrm{CH}_{2}-\mathrm{N}\left(\mathrm{CH}_{3}\right)_{2}, 2.27-2.35\right)$ of PDMAEMA.

Synthesis of poly[(qDMAEMA $95-$ stat-MMA90)-b-(BiBEM ${ }_{400}-$ stat $\left.^{-M M A} 400\right)-b-$ (DMAEMA95-stat-MMA90)] (qBAB macroinitiator, qBAB MI). The polymer, qBAB (2.38 g, containing $1.96 \mathrm{mmol}$ of HEMA-TMS units), potassium fluoride $(0.139 \mathrm{~g}, 2.35 \mathrm{mmol})$ and 2,6-di-tert-butylphenol (40.4 mg, $0.196 \mathrm{mmol})$ were placed in a $100 \mathrm{ml}$ round bottom flask. The flask was sealed, flushed with nitrogen, and dry DMF $(30 \mathrm{~mL})$ was added. The mixture was cooled in an ice bath to $0{ }^{\circ} \mathrm{C}$, tetrabutylammonium fluoride solution in THF $(1 \mathrm{M}, 0.02$ $\mathrm{mL}, 0.02 \mathrm{mmol}$ ) was injected to the flask, followed by the drop-wise addition of 2bromoisobutyryl bromide $(0.29 \mathrm{~mL}, 2.35 \mathrm{mmol})$. After the addition the reaction mixture was 
allowed to reach room temperature and stirring was continued for $24 \mathrm{~h}$. The product was purified by dialysis against DMF using dialysis tubes with a pore size molar mass cut off 10 kDa..

Synthesis of poly[(qDMAEMA98-stat-MMA 65$)-b-\left(\left(B_{1 B E M-g-p o l y(M P C}\right)_{35}\right)_{459}$-statMMA $_{370}$ )-b-(qDMAEMA98-stat-MMA 65$\left.)\right]$ (triblock BB polymer). A dry $50 \mathrm{~mL}$ Schlenk flask was charged with polymer qBAB MI (32.6 mg in $3 \mathrm{wt} \%$ DMF stock solution, containing $0.056 \mu \mathrm{mol}$ of BiBEM), 2-methacryloyloxyethyl phosphorylcholine (5.00 g, 17.0 mmol), 2,2'-bipyridyl (30.0 mg, $0.192 \mathrm{mmol}), \mathrm{Cu}^{\mathrm{II}} \mathrm{Cl}_{2}$ (1.5 mg, $\left.0.011 \mathrm{mmol}\right)$, and methanol $(22.0 \mathrm{~mL})$. The solution was degassed by three freeze-pump-thaw cycles. After the final cycle, $\mathrm{Cu}{ }^{\mathrm{I}} \mathrm{Cl}(8.4 \mathrm{mg}, 0.085 \mathrm{mmol})$ was added followed by thawing reaction mixture under nitrogen atmosphere, and the flask was immersed in an oil bath thermostated at $45{ }^{\circ} \mathrm{C}$. The reaction was stopped when monomer conversion reached $11.8 \%$. The resulting brush was purified by dialysis against $\mathrm{MeOH}$ for $48 \mathrm{~h}$ using dialysis tubes with a pore size molar mass cut off $10 \mathrm{kDa}$. The Monomer conversion was calculated by ${ }^{1} \mathrm{H}$ NMR analysis, resulting in the average degree of polymerization of the side chains, DP 35. 


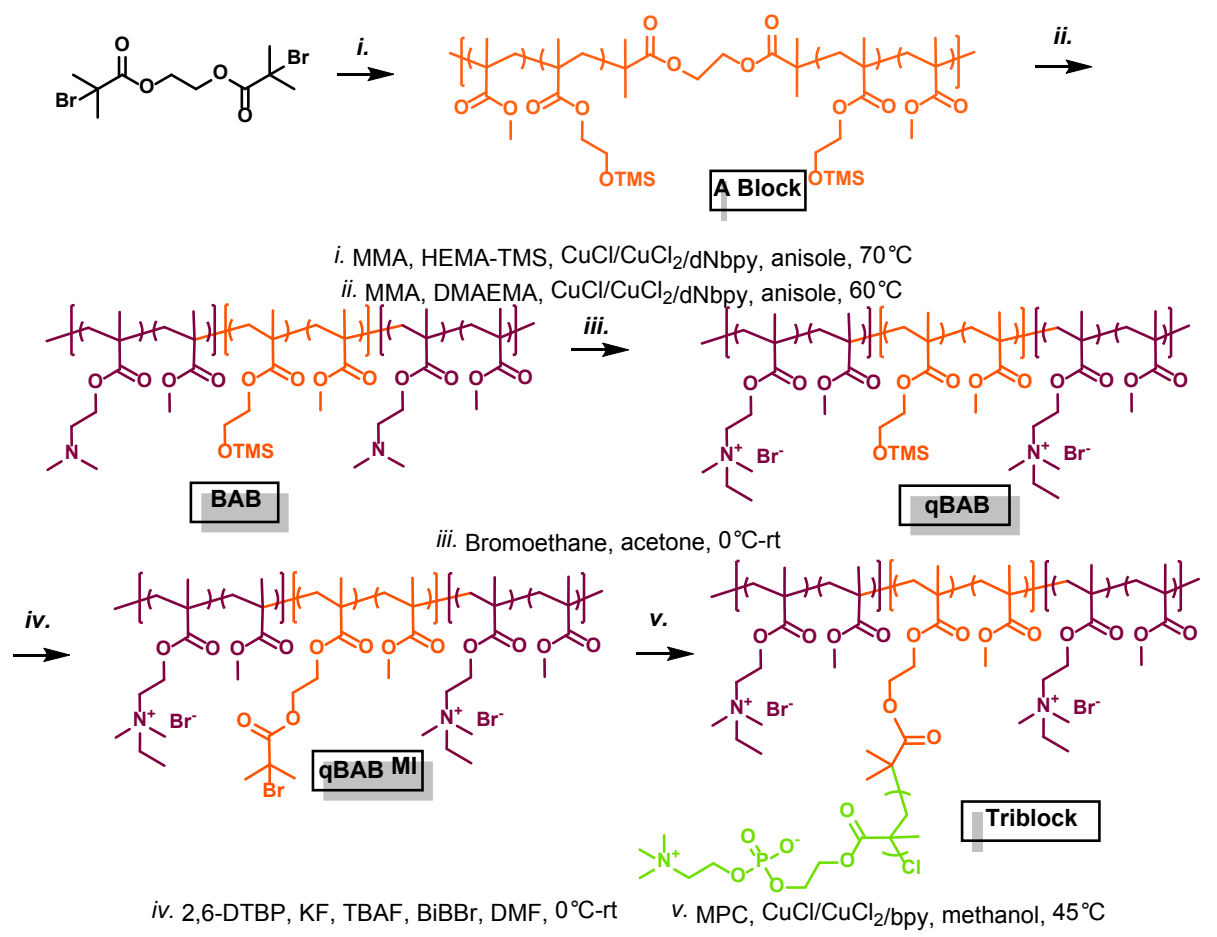

Figure S2. Synthesis of the triblock BB polymer

\section{Diblock BB polymer synthesis (Figure S3)}

Synthesis of poly(HEMA-TMS) $)_{551}$-co-PMMA 338 (A block).: A dried round bottom flask was charged with BBiB (3.4 $\mu \mathrm{L}, 0.023 \mathrm{mmol})$, dNbpy (112.8 mg, $0.276 \mathrm{mmol})$, HEMA-TMS (10.0 mL, $45.9 \mathrm{mmol})$, MMA (4.9 mL, $45.9 \mathrm{mmol})$ and anisole $(3.0 \mathrm{~mL})$. The solution was bubbled with argon for $30^{\prime} . \mathrm{Cu} \mathrm{Br}(0.0158 \mathrm{~g}, 0.110 \mathrm{mmol})$, and $\mathrm{Cu}^{\mathrm{II}} \mathrm{Br}_{2}(0.0061 \mathrm{~g}, 0.028 \mathrm{mmol})$ were charged in a dried 50 $\mathrm{mL}$ round bottom flask and 3 argon-vacuum cycles were performed to remove oxygen. The flask was sealed, and then immersed in an oil bath at $40{ }^{\circ} \mathrm{C}$. After bubbling, the monomer solution was injected into the catalyst solution. Reaction was stopped after $14 \mathrm{~h}$ via exposure to air, reaching the degree of polymerization of the product 500 . The monomers consumption was calculated by the integration of MMA and HEMA-TMS vinyl groups signal $\left(\mathrm{CHH}=\mathrm{C}-\mathrm{CH}_{3}, 6.11 \mathrm{ppm}\right.$ or $\left.5.56 \mathrm{ppm}\right)$ against the internal standard (anisole, $o, p-\mathrm{Ar}-\mathrm{H}, 6.91 \mathrm{ppm}$ ). The product $\mathbf{A}$ was purified by three precipitations from methanol, dried under vacuum overnight at room temperature, and analyzed by GPC and ${ }^{1} \mathrm{H}$ NMR spectroscopy. The ratio of PMMA ( $s$, broad, CO-O-CH$H_{3}, 3.54-3.68$ ppm) to P(HEMA-TMS) ( $s$, broad, OCO-CH$H_{2}, 3.90-4.17 \mathrm{ppm}$ ) signals gave the polymer composition. 
Synthesis of (PDMAEMA ${ }_{94}$-stat-PMMA $\left.{ }_{153}\right)-b$-[P(HEMA-TMS ${ }_{551}$-stat-PMMA (P38 (BA): A dried round bottom flask was charged with A block (1.0 g, $0.0094 \mathrm{mmol})$, dNbpy (70 mg, $0.17 \mathrm{mmol}$ ), DMAEMA (1.2 mL, 7.0mmol), MMA $(0.75 \mathrm{~mL}, 7.0 \mathrm{mmol})$ and anisole $(4.0 \mathrm{~mL})$. The solution was bubbled with argon for $30^{\prime} . \mathrm{Cu}^{\mathrm{I}} \mathrm{Cl}(0.0074 \mathrm{~g}, 0.0752 \mathrm{mmol})$, and $\mathrm{Cu}^{\mathrm{II}} \mathrm{Cl}_{2}(0.0010 \mathrm{~g}, 7.46 \mu \mathrm{mol})$ were charged in a dried $25 \mathrm{~mL}$ round bottom flask and 3 argon-vacuum cycles were performed to remove oxygen. The flask was sealed, and then immersed in an oil bath at $60^{\circ} \mathrm{C}$. After bubbling, the monomer solution was injected into the catalyst solution. Reaction was stopped after $48 \mathrm{~h}$ via exposure to air. The product was diluted in dichloromethane, passed through a neutral alumina column, concentrated under vacuum and precipitated twice from hexanes and water. The solvent was removed under vacuum and the product was dried overnight under vacuum at room temperature. The structure of the polymer was determined from the ratio of selected polymer signals: PMMA ( $s$, broad, CO-O-CH , 3.54-3.68 ppm),P(HEMA-TMS) ( $s$, broad, $\left.\mathrm{O}-\mathrm{Si}\left(\mathrm{CH}_{3}\right)_{3}, 0.11-0.21 \mathrm{ppm}\right)$ and PDMAEMA ( $m, \mathrm{CH}_{2^{-}}$ $\left.\mathrm{NMe}_{2}, 2.55-2.65 \mathrm{ppm}\right)$.

Synthesis of [PBiBEM-stat-PMMA]-b-(PDMAEMA-stat-PMMA) (BA macroinitiator, BA MI): BA $(0.1840 \mathrm{~g})$, potassium fluoride $(0.030 \mathrm{~g}, 0.52 \mathrm{mmol})$ and 2,6-di-tert-butylphenol $(0.0090 \mathrm{~g}, 0.0439$ mmol) were placed in a $20 \mathrm{ml}$ round bottom flask. The flask was sealed, flushed with argon, and finally anhydrous THF $(7 \mathrm{~mL})$ was added. The mixture was cooled in an ice bath to $0{ }^{\circ} \mathrm{C}$, tetrabutylammonium fluoride solution in THF $(1 \mathrm{M}, 0.44 \mathrm{~mL}, 0.44 \mathrm{mmol})$ was injected to the flask, followed by a drop-wise addition of 2-bromoisobutyryl bromide $(0.121 \mathrm{~g}, 65 \mu \mathrm{L}, 0.526 \mathrm{mmol})$. After the addition the reaction mixture was allowed to reach room temperature and stirring was continued for $24 \mathrm{~h}$. The solution was passed through a short column filled with basic alumina, precipitated into hexanes and then methanol:water $(70: 30, \mathrm{v} / \mathrm{v} \%)$ three times. The filtrate was dried under vacuum overnight at room temperature.

Synthesis of [(PBiBEM-g-PMPC)-stat-MMA]-b-(PDMAEMA-stat-PMMA) (BAC): A dry $10 \mathrm{~mL}$ round bottom flask was charged with polymer BA MI (2mg), 2-methacryloyloxyethyl phosphorylcholine (MPC)(0.2540 g, 0.860mmol), 2,2'-bipyridyl (bpy) (22 mg, $14.23 \mu \mathrm{mol}), \mathrm{Cu}^{\mathrm{I}} \mathrm{Cl}$ (6 mg, $60 \mu \mathrm{mol})$, and copper (II) chloride $\left(\mathrm{Cu}^{\mathrm{II}} \mathrm{Cl}_{2}\right)(1 \mathrm{mg}, 7.40 \mu \mathrm{mol})$. A dry $10 \mathrm{~mL}$ round bottom flask 
was charged with methanol $(3.0 \mathrm{~mL})$ and anisole $(500 \mu \mathrm{L})$. The solution was bubbled with argon for 15'. The flask was sealed, and then immersed in an oil bath at $50{ }^{\circ} \mathrm{C}$. After bubbling, the solvent solution was injected into the catalyst/monomer solution. Time of reaction was determine thanks to MPC conversion measurement by $1 \mathrm{HNMR}$ to reach a DP of 35 . Reaction was then stopped via exposure to air achieving PMPC diblock brush. The resulting brush was purified by ultrafiltration against $\mathrm{MeOH}$ under pressure using regenerated cellulose membrane (Milli Pore) with a pore size molar mass cut off 30,000 Da.

\section{Synthesis of [(PBiBEM-g-PMPC)-stat-MMA]-b-(PqDMAEMA-stat-PMMA) (diblock BB} polymer) was placed in $20 \mathrm{~mL}$ vial and dissolved in Methanol $(10 \mathrm{~mL})$. The solution was cooled in an ice bath to $0{ }^{\circ} \mathrm{C}$, followed by a slow addition of bromoethane $(0.5 \mathrm{~mL}, 6.7 \mathrm{mmol})$. The reaction was stirred at room temperature for the next $48 \mathrm{~h}$. The solvent and the unreacted reagent were evaporated under gentle pressure and solvent was exchanged for water by ultrafiltration. The polymer was freezedried and stored at $-20^{\circ} \mathrm{C}$ in a dark container. The quantitative quaternization of $-\mathrm{NMe}_{2}$ groups of diblock BB polymer was determined by ${ }^{1} \mathrm{H}$ NMR.

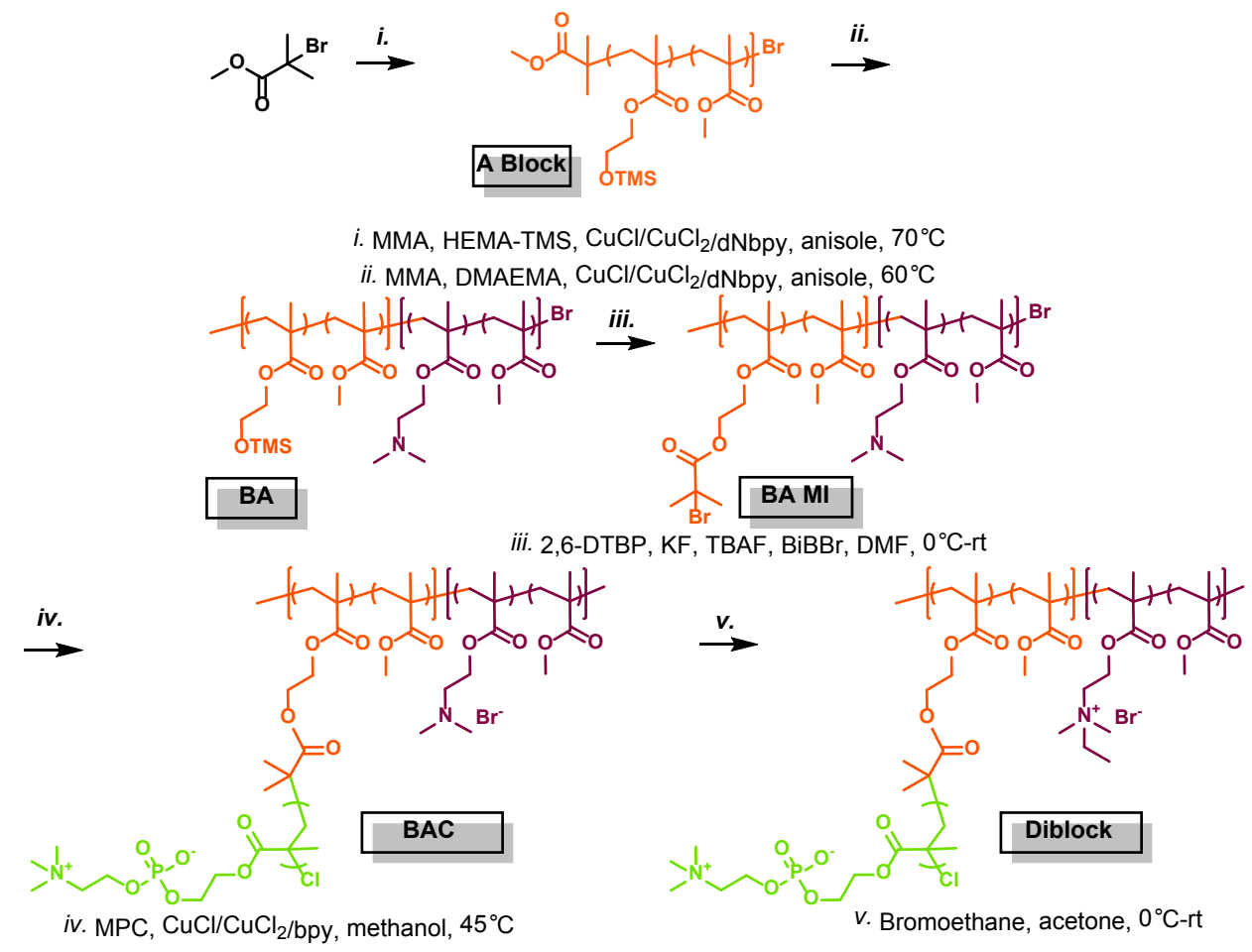

Figure S3. Synthesis of the diblock BB polymer 